Themed Issue: Drug Addiction - From Basic Research to Therapies

Guest Editors - Rao Rapaka and Wolfgang Sadée

\title{
Endocannabinoid Mechanisms of Pain Modulation
}

\author{
Submitted: June 29, 2006; Accepted: July 19, 2006; Published: November 17, 2006
}

Andrea G. Hohmann ${ }^{1}$ and Richard L. Suplita, $\mathrm{II}^{1}$

${ }^{1}$ Neuroscience and Behavior Program, Department of Psychology, University of Georgia, Athens, GA 30602-3013

\section{AbSTRACT}

Cannabinoids are antinociceptive in animal models of acute, tissue injury-, and nerve injury-induced nociception. This review examines the biology of endogenous cannabinoids (endocannabinoids) and behavioral, neurophysiological, and neuroanatomical evidence supporting the notion that cannabinoids play a role in pain modulation. Behavioral pharmacological approaches, in conjunction with the identification and quantification of endocannabinoids through the use of liquid and gas chromatography mass spectrometry, have provided insight into the functional roles of endocannabinoids in pain modulation. Here we examine the distribution of cannabinoid receptors and endocannabinoid-hydrolyzing enzymes within pain modulatory circuits together with behavioral, neurochemical, and neurophysiological studies that suggest a role for endocannabinoid signaling in pain modulation. This review will provide a comprehensive evaluation of the roles of the endocannabinoids 2-arachidonoylglycerol and anandamide in stress-induced analgesia. These findings provide a functional framework with which to understand the roles of endocannabinoids in nociceptive processing at the supraspinal level.

KEYWORDS: 2-arachidonoylglycerol, anandamide, CB1, fatty acid amide hydrolase, monoacylglycerol lipase, periaqueductal gray, rostral ventromedial medulla

\section{INTRODUCTION}

The discovery, cloning, and characterization of cannabinoid receptors, ${ }^{1-3}$ along with the isolation of endogenous ligands for these receptors, such as anandamide 4 and 2-arachidonoylglycerol (2-AG), 5,6 established the existence of an endocannabinoid neuromodulatory system. Cannabinoid receptors occur in high densities in the rodent brain ( $>1 \mathrm{pmol} / \mathrm{mg}$ protein). ${ }^{2}$ The heterogeneous distribution of cannabinoid receptors in the central nervous system ${ }^{2,7}$

\section{Corresponding Author: Andrea G. Hohmann,}

Neuroscience and Behavior Program, Department of

Psychology, University of Georgia, Athens, GA 30602.

Tel: (706) 542-2252; Fax: (706) 542-3275;

E-mail: ahohmann@uga.edu suggests a neuroanatomical basis for the profound behavioral effects induced by exogenous cannabinoids. The cannabinoid system is thus a major neurochemical system whose functional significance has only recently been explored. Cannabinoid receptors are localized in neuroanatomical regions subserving transmission and modulation of pain signals, such as the periaqueductal gray (PAG), the rostral ventromedial medulla (RVM), ${ }^{2,7}$ and the dorsal horn of the spinal cord. ${ }^{7}$ These findings suggest that endocannabinoids play a key role in central nervous system modulation of pain signaling. This review will focus on elucidating the pain modulatory functions of cannabinoids and endocannabinoids mediated primarily at the supraspinal level.

\section{CANNABINOID RECEPTOR SUBTYPES}

Two subtypes of cannabinoid receptors $-\mathrm{CB}_{1}$ and $\mathrm{CB}_{2}-$ have been identified. $\mathrm{CB}_{1}$ is enriched in the brain. ${ }^{3,8,9} \mathrm{By}$ contrast, $\mathrm{CB}_{2}$ is mainly expressed in immune tissues, including the spleen, tonsils, monocytes, and $\mathrm{B}$ and $\mathrm{T}$ cells $\mathrm{s}^{10-12}$ and is found only at low levels in neurons of the central nervous system. ${ }^{8,9,11}$ In pathological pain states, $\mathrm{CB}_{2}$ messenger RNA (mRNA) is also detected in the lumbar dorsal horn concurrently with the appearance of activated microglia. ${ }^{13}$ $\mathrm{CB}_{1}$ is negatively coupled to adenylate cyclase through $\mathrm{Gi} / \mathrm{o}$ proteins. ${ }^{14,15}$ Activation of these receptors inhibits $\mathrm{N}$ - and P/Q-type calcium channels ${ }^{16,17}$ and activates inward rectifying potassium ${ }^{18}$ and potassium $\mathrm{A}^{19}$ channels. $\mathrm{CB}_{2}$ is also negatively coupled to adenylate cyclase but is not coupled to calcium channels. ${ }^{14}$ These signal transduction properties suggest that activation of $\mathrm{CB}_{1}$ suppresses neuronal excitability and neurotransmitter release by modulating calcium and potassium conductances.

This review will examine evidence suggesting that endocannabinoids act at $\mathrm{CB}_{1}$ receptors in the central nervous system to modulate pain processing. A more extensive review of the role of $\mathrm{CB}_{1}$ receptor activation in modulating acute and sustained nociception at spinal and peripheral levels is available elsewhere. ${ }^{20,21} \mathrm{~A}$ role for peripheral $\mathrm{CB}_{1}$ and $\mathrm{CB}_{2}$ receptors in modulating acute, ${ }^{22}$ tissue injury-, ${ }^{23-29}$ and nerve injury-induced ${ }^{30}$ nociception has recently been demonstrated following systemic and local hind paw injections of $\mathrm{CB}_{2}$-selective agonists. Interested readers are referred to recent reviews of peripheral cannabinoid antinociceptive mechanisms. ${ }^{20,31-34}$ 


\section{ENDOCANNABINOIDS}

Several putative endocannabinoids have been isolated in the brain, including anandamide, 2-AG, noladin ether, virodhamine, and $N$-arachidonoyldopamine (NADA). Other endogenous cannabinergic compounds include the related fatty acid derivatives oleamide, palmitoylethanolamide, and a novel family of arachidonoyl amino acids. These substances lack affinity for cannabinoid receptors but appear to facilitate endocannabinoid function. The functional roles of these latter compounds remain poorly understood and are beyond the scope of this review. Because anandamide and 2-AG are the best characterized of the endocannabinoids isolated thus far, this review will focus on understanding the role of these endocannabinoids in pain modulation.

Anandamide ${ }^{4}$ and $2-\mathrm{AG}^{5,6,35}$ are thought to be produced upon demand (ie, by activity-dependent or receptorstimulated cleavage of membrane lipid precursors) and to be released from cells immediately after their production (for review, see Piomelli ${ }^{36}$ ). Anandamide is synthesized in vitro in a 2-step process (Figure 1; for review, see Piomelli ${ }^{36}$ ). First, the phospholipid precursor $N$-arachidonoylphosphatidylethanolamine (NAPE) is formed from phosphatidylethanolamine through a mechanism that is both $\mathrm{Ca}^{2+}$ and cyclic AMP dependent, and catalyzed by the enzyme $N$-acyltransferase. Second, NAPE is believed to be hydrolyzed by a NAPE-specific phospholipase D-an enzyme that remains molecularly uncharacterized - to generate anandamide and the metabolic intermediate phosphatidic acid. Anandamide shows preferential affinity for $\mathrm{CB}_{1}$

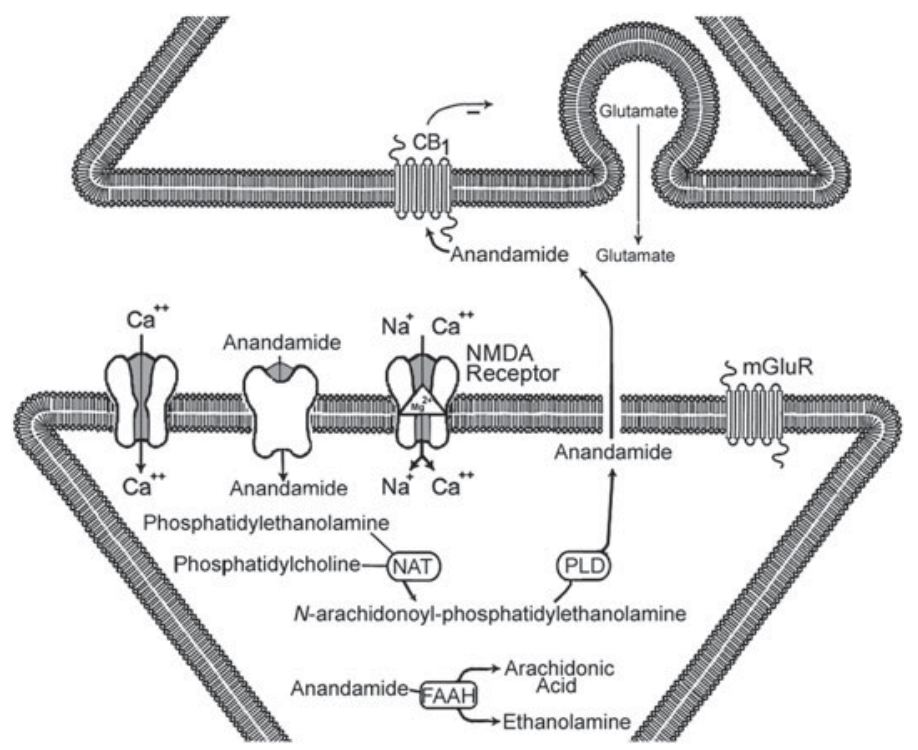

Figure 1. Hypothetical model showing pathways of anandamide formation and deactivation. FAAH indicates fatty acid amide hydrolase; mGluR, metabotropic glutamate receptor; NAPE, $\mathrm{N}$-arachidonoyl-phosphatidylethanolamine; NAT, Nacyltransferase; NMDA, $N$-methyl-D-aspartic acid; and PLD, phospholipase D.
$\left(\mathrm{K}_{\mathrm{i}}\left[\mathrm{CB}_{1} \mathrm{vs} \mathrm{CB}_{2}\right]=89 \mathrm{vs} 371 \mathrm{nM}\right)$ in vitro and acts as a lowaffinity agonist at vanilloid TRPV1 receptors. ${ }^{37-39}$ Systemic administration of exogenous anandamide produces antinociception, suggesting that the endocannabinoid may also suppress pain under physiological conditions. This effect, however, is not reliably blocked by the selective $\mathrm{CB}_{1}$ antagonist SR141716A (rimonabant),${ }^{40,41}$ likely owing to the fact that anandamide is readily metabolized in vivo by fatty acid amide hydrolase (FAAH) into ethanolamine and arachidonic acid.

In vitro experiments suggest that 2-AG formation (for review, see Piomelli ${ }^{36}$ ) occurs via successive activation of 2 enzymes (Figure 2). First, the 2-AG precursor 1,2-diacylglycerol (DAG) is formed from phospholipase $\mathrm{C}-$-mediated hydrolysis of membrane phosphoinositides. Newly formed DAG may subsequently be hydrolyzed by DAG-lipase (DGL) to yield 2-AG. DAG can alternatively be phosphorylated by DAG kinase to yield phosphatidic acid. Therefore, DGL-mediated hydrolysis of DAG is likely the first committed step in 2-AG biosynthesis (for review, see Piomelli $\left.{ }^{36}\right)$. In brain slices and cultured cells, 2-AG formation may be stimulated by neural activity, ${ }^{35}$ membrane depolarization, ${ }^{42}$ or pharmacological activation of $\mathrm{G}$ proteincoupled receptors such as group I metabotropic glutamate receptors. ${ }^{43} 2-\mathrm{AG}$ is a naturally occurring 2-monoacylglycerol that activates both $\mathrm{CB}_{1}$ and $\mathrm{CB}_{2}$ receptors. ${ }^{5,6}$ Although brain concentrations of 2-AG are 170-fold higher than those of anandamide, ${ }^{35}$ the role of endogenous $2-\mathrm{AG}$ in pain modulation is just beginning to be appreciated. 2-AG has been postulated to be the true natural ligand for cannabinoid receptors, with cannabinoid receptors serving primarily as 2-AG receptors. ${ }^{44,45}$ Exogenous 2-AG, administered systemically, suppresses noxious stimulus-induced responding in the tail-flick assay, ${ }^{5}$ suggesting that endogenous

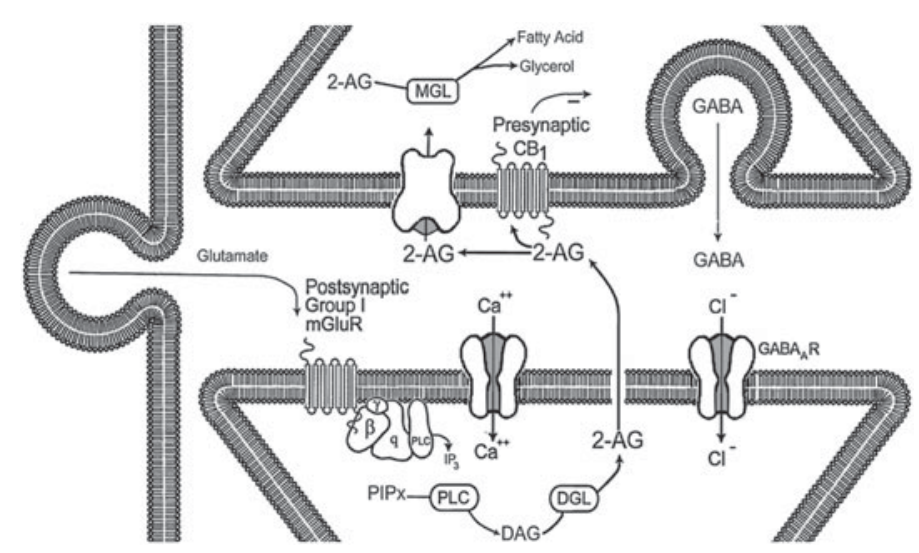

Figure 2. Hypothetical model showing pathways of 2-AG formation and deactivation. 2-AG indicates 2-arachidonoylglycerol; DAG, diacylglycerol; DGL, diacylglycerol lipase; GABA, ; MGL, monoacylglycerol lipase; mGluR, metabotropic glutamate receptor; PLC, phospholipase C, and PIPx, phospholipid precursors. 
2-AG may suppress pain responding under physiological conditions. Behavioral responses to 2-AG are also enhanced by related, endogenous 2-acylglycerols, which fail to show significant activity in any of the tests employed when administered alone ${ }^{46}$ This "entourage effect" is likely to help regulate the activity of endocannabinoids in the nervous system $^{46}$ : competing for the same enzyme for hydrolysis may potentiate endocannabinoid actions.

\section{ENDOCANNABINOID DEGRADING ENZYMES}

Three of the 5 putative endocannabinoids - anandamide, 2-AG, and NADA - are susceptible to degradation by FAAH, ${ }^{47-50}$ although a second enzyme, monoacylglycerol lipase (MGL), ${ }^{51}$ catalyzes hydrolysis of $2-A G$ in vivo. ${ }^{52}$ Immunocytochemical methods have been employed to map the distribution of FAAH in the brain. ${ }^{53-55}$ The anatomical correspondence of FAAH and $\mathrm{CB}_{1}$ mRNA also supports the hypothesis that endocannabinoids act as retrograde messengers. ${ }^{54}$ Recent electrophysiological studies have provided confirmation of this hypothesis. ${ }^{56,57}$ Significantly, immunocytochemical studies have demonstrated FAAH expression in the ventral posterior lateral nucleus of the thalamus, ${ }^{53-55}$ which is the termination zone of the spinothalamic tract. This pathway is the major source of ascending nociceptive information to the brain. Furthermore, FAAH has been identified in Lissauer's tract and in neurons of the superficial spinal cord dorsal horn (ie, in close proximity to the termination zone of nociceptive primary afferents). These observations confirm that a mechanism for endocannabinoid deactivation is present in regions of the central nervous system implicated in nociceptive processing and further support the notion that endocannabinoids play a role in pain modulation.

Although FAAH reportedly metabolizes $2-\mathrm{AG}$ in vitro, ${ }^{58}$ MGL is likely to play the predominant role in 2-AG deactivation. ${ }^{51}$ MGL is a serine hydrolase that converts monoglycerides to fatty acids and glycerol. Northern blot, immunocytochemical, and in situ hybridization studies reveal that MGL is heterogeneously distributed in the rat brain, with the highest levels observed in the cortex, the thalamus, the hippocampus, and the cerebellum. ${ }^{51}$ Ultrastructural studies suggest that MGL is localized predominantly if not exclusively on axon terminals. ${ }^{59}$ The recent development of pharmacological inhibitors of MGL such as URB602 has provided pharmacological tools for studying the functions of endogenous 2-AG in pain modulation, as described later in this review. ${ }^{52}$ In vitro studies suggest that overexpression of MGL attenuates 2-AG accumulation in rat cortical neurons without altering anandamide accumulation. ${ }^{51}$ Moreover, virally mediated RNA silencing of MGL is associated with marked enhancements of both basal and $\mathrm{Ca}^{2+}$-stimulated 2-AG levels in HeLa cells. ${ }^{60}$ Activation of mGlu5 receptors stimulates the formation of 2-AG (but not anandamide) in cultured cells derived from rat corticostriatal and hippocampal slices. ${ }^{43}$ This formation of 2-AG is calcium-dependent and catalyzed by phospholipase $\mathrm{C}$ and 1,2-diacylglycerol lipase. ${ }^{43}$ Also, the metabotropic glutamate 5 (mGlu5) receptor antagonist 2-methyl-6-(phenylethynyl)-pyridine (MPEP) prevents $2-\mathrm{AG}$ formation induced by the group I mGlu receptor agonist 3,5-dihydroxyphenylglycine (DHPG). ${ }^{43}$ More work, however, is necessary to determine whether the same processes control 2-AG formation in vivo.

The antinociceptive effects of exogenous 2-AG are preserved in FAAH(-/-) mice, ${ }^{61}$ suggesting that FAAH does not catalyze 2-AG deactivation in vivo. Unlike anandamide and oleamide, monoacylglycerol lipids such as 2-AG exhibited equivalent hydrolytic activity in $\mathrm{FAAH}(+/+)$ and $(-/-)$ mice. ${ }^{61}$ These observations formed the basis for the conclusion that FAAH is an important regulator but not mediator of fatty acid amide activity in vivo. ${ }^{61}$

Transgenic approaches involving FAAH and $\mathrm{CB}_{1}$ knockouts have recently been used in conjunction with pharmacological approaches to better evaluate the role of endocannabinoids in pain modulation. Mutant mice lacking the $\mathrm{CB}_{1}$ gene fail to show typical antinociceptive responses to prototypical cannabinoid agonists.9,62 It should be acknowledged, however, that high doses of $\Delta^{9}$-tetrahydrocannabinol do exhibit a $\mathrm{CB}_{1}$-independent antinociception, ${ }^{9}$ although the receptor mechanism underlying this effect has not been evaluated. Cravatt et al developed mice lacking the FAAH gene and observed that these animals exhibited enhanced antinociceptive behavior following exogenous administration of anandamide. ${ }^{63}$ Importantly, these enhancements of antinociception were blocked by the selective $\mathrm{CB}_{1}$ antagonist rimonabant, providing compelling evidence that a $\mathrm{CB}_{1}$-dependent process is responsible for FAAHmediated anandamide hydrolysis. Furthermore, Cravatt et al ${ }^{63}$ observed tonic centrally mediated $\mathrm{CB}_{1}$-dependent analgesia in FAAH(-/-) mice, an effect likely due to the absence of this key enzyme, which catalyzes hydrolysis of fatty acid amides such as anandamide. ${ }^{63,64}$ The behavioral phenotype was associated with a 15 -fold increase in endogenous brain levels of anandamide in the FAAH(-/-) mice relative to FAAH $(+/+)$ mice. ${ }^{63}$ When mice lacking FAAH were treated with exogenous anandamide, they exhibited profound $\mathrm{CB}_{1}$ dependent behavioral responses, including hypomotility, analgesia, catalepsy, and hypothermia. The generation of mutant mice that are incapable of synthesizing or inactivating 2-AG should further elucidate roles of this endocannabinoid in pain modulation.

\section{CANNABINOID RECEPTOR PHARMACOLOGY AND EXOGENOUS CANNABINOID LIGANDS}

The development of competitive antagonists ${ }^{65}$ and selective agonists for $\mathrm{CB}_{1}$ has provided important pharmacological 


\section{The AAPS Journal 2006; 8 (4) Article 79 (http://www.aapsj.org).}

tools for investigating the biological functions of cannabinoids in the nervous system. SR141716A (rimonabant) shows high affinity for cannabinoid receptors in the brain $\left(\mathrm{K}_{\mathrm{d}}=0.23 \mathrm{nM}\right)^{65}$ but displays negligible affinity for $\mathrm{CB}_{2}\left(\mathrm{~K}_{\mathrm{i}}\right.$ $\left[\mathrm{CB}_{1}\right.$ vs $\left.\mathrm{CB}_{2}\right]=5.6 \mathrm{nM}$ vs $\left.>1 \mu \mathrm{M}\right) .{ }^{66}$ At high concentrations, rimonabant has been shown to inhibit vanilloid TRPV1 (formerly VR1) receptors. AM251 is a selective, competitive $\mathrm{CB}_{1}$ antagonist $\left(\mathrm{K}_{\mathrm{i}}\left[\mathrm{CB}_{1}\right.\right.$ vs $\left.\mathrm{CB}_{2}\right]=7.5 \mathrm{nM}$ vs $>2 \mu \mathrm{M})^{67}$ devoid of vanilloid activity. Potent cannabinoid agonists $\mathrm{CP} 55940\left(\mathrm{~K}_{\mathrm{i}}=0.6 \mathrm{nM}\right.$ at $\mathrm{CB}_{1}$ and $\left.\mathrm{CB}_{2}\right)$, HU210 $\left(\mathrm{K}_{\mathrm{i}}\left[\mathrm{CB}_{1}\right.\right.$ vs $\left.\mathrm{CB}_{2}\right]=0.73$ vs $\left.0.22 \mathrm{nM}\right)$, and WIN55212-2 ( $\mathrm{K}_{\mathrm{i}}$ $\left[\mathrm{CB}_{1}\right.$ vs $\left.\mathrm{CB}_{2}\right]=1.9$ vs $0.3 \mathrm{nM}$ ) show high affinity for $\mathrm{CB}_{1}$ and $\mathrm{CB}_{2}$ and show marked improvements in potency compared with $\Delta^{9}$-tetrahydrocannabinol $\left(\Delta^{9}\right.$-THC), the prototypic classical cannabinoid. Selective competitive antagonists and high-affinity agonists have been used both to characterize the roles of cannabinoids in pain signaling and to map the sites of endocannabinoid action within the nervous system.

Studies relying upon the delivery of exogenous compounds that directly activate or block cannabinoid receptors have been indispensable for the initial assessment of the functional role of cannabinoid receptor activation in pain modulation. However, these studies do not provide direct evidence that endocannabinoids mediate these same functions under physiological conditions. More recently, the development of drugs that inhibit the enzymatic degradation of endocannabinoids (ie, through inhibition of FAAH or MGL) has facilitated research examining the functional consequences of activation of the body's endogenous system. URB59768 is a well-characterized irreversible inhibitor of FAAH $\left(\mathrm{IC}_{50}=\right.$ 4.6 nM) that lacks significant affinity for $\mathrm{CB}_{1}$ and $\mathrm{CB}_{2}$ receptors and does not affect MGL, acetyl-cholinesterase, butyryl-cholinesterase, or the anandamide membrane transporter at concentrations up to $300 \mu \mathrm{M}$. Arachidonoylserotonin $^{69}$ is a novel FAAH inhibitor that inhibits anandamide hydrolysis $\left(\mathrm{IC}_{50}=5.6 \mu \mathrm{M}\right)$, lacks affinity for $\mathrm{CB}_{1}$, and does not significantly affect the cellular uptake of anandamide at $25 \mu \mathrm{M}$. MGL can be inhibited by a variety of nonselective serine hydrolase inhibitors (eg, methyl arachidonoyl fluorophosphonate). More recently, 2 selective inhibitors of MGL, URB602 ${ }^{52}$ and URB754, ${ }^{70}$ have been described. URB602 inhibits rat brain MGL $\left(\mathrm{IC}_{50}=28 \pm 4 \mu \mathrm{M}\right)$ through a noncompetitive mechanism, does not affect FAAH activity or anandamide levels, does not affect the activity of lipidmetabolizing enzymes such as diacylglycerol lipase ${ }^{35}$ and cyclooxygenase- $2,{ }^{71}$ and does not influence the binding of $\left[{ }^{3} \mathrm{H}\right]-$ WIN55212-2 to $\mathrm{CB}_{1}$ or $\mathrm{CB}_{2}$ receptors $\left(\mathrm{IC}_{50} \geq 5 \mu \mathrm{M}\right)$ or $\left[{ }^{35} \mathrm{~S}\right]-\mathrm{GTP}-\gamma-\mathrm{S}$ to rat cerebellar membranes. ${ }^{52}$ The effects of URB754 on pain modulation have not been examined.

Cellular uptake of anandamide reportedly involves facilitated diffusion, ${ }^{72}$ although a specific transporter has yet to be cloned. Kinetics studies suggest the presence of an anan- damide membrane transporter, ${ }^{72}$ and pharmacological studies using inhibitors of anandamide transport ${ }^{52,72}$ have supported the notion that anandamide transport inhibition has a role in modulating endocannabinoid tone. Among the most commonly employed drugs of this class are AM404, which also inhibits FAAH activity, ${ }^{73}$ and VDM11. While AM404 ${ }^{74}$ activates TRPV1 receptors at low concentrations, VDM11 15 does not. VDM11 inhibits the cellular uptake of anandamide $\left(\mathrm{IC}_{50}=1-11 \mu \mathrm{M}\right)$, does not affect FAAH, and does not bind cannabinoid receptors at biologically relevant concentrations. Recently, a potent new competitive inhibitor of anandamide uptake, LY2318912, ${ }^{72}$ was used to radiolabel the anandamide transporter binding site in rat cerebellum. Systemic administration of LY2318912 also induced a 5fold elevation in brain anandamide levels. Moreover, LY2318912 diminished nociceptive behavior in the formalin test, with no concomitant expression of gross motor deficits typical of administration of direct cannabinoid agonists. ${ }^{72}$

\section{ANTINOCICEPTIVE EFFECTS OF EXOGENOUS CANNABINOIDS}

Preclinical behavioral studies using different types of noxious stimulation (ie, thermal, mechanical, and chemical; for review, see Walker and Hohmann ${ }^{21}$ ) have demonstrated that cannabinoids effectively induce antinociception. In 1899, Dixon $^{76}$ demonstrated that delivery of cannabis smoke to dogs produced a failure to respond to pin pricks. Seminal studies on cannabinoid-induced antinociception by Bicher and Mechoulam ${ }^{77}$ and Kosersky et al ${ }^{78}$ provided a foundation for subsequent work that verified the ability of cannabinoids to profoundly suppress behavioral reactions to acute noxious stimuli and inflammatory and nerve injury-induced pain. The potency and efficacy of cannabinoids in producing antinociception is comparable to that of morphine. ${ }^{79,80}$ However, cannabinoids induce profound motor deficits, including immobility and catalepsy, ${ }^{81}$ which are a confound for behavioral studies that assess motor responses to noxious stimuli. Many recent studies of cannabinoid antinociception compensate for this limitation by additionally assessing behavioral measures of immobility and catalepsy to provide intrinsic controls for cannabinoid-induced changes in motor responding. Nonetheless, behavioral studies alone are not sufficient to demonstrate that cannabinoids suppress the processing of nociceptive information. An extensive literature now demonstrates that cannabinoids suppress nociceptive transmission, thus providing a compelling argument for the existence of endocannabinoid mechanisms of pain modulation.

Studies employing the systemic administration of cannabinoids have been useful in characterizing the antinociceptive effects of cannabinoids in animal models of acute and persistent nociception. The antinociceptive effects elicited by 
natural, synthetic, and exogenously administered endocannabinoids, along with the blockade of these effects by pharmacological and genetic disruptions of $\mathrm{CB}_{1}$ activity, strongly suggest that cannabinoids have a specific physiological role in modulating pain sensitivity. Limitations of these approaches include the inability to localize the sites of action of cannabinoids and the failure to identify which endocannabinoids are involved in pain modulation. To address the first limitation, several important studies have used site-specific microinjections of cannabinoids into brain regions implicated in the processing and regulation of nociceptive signals. The second limitation has been addressed directly by identifying and quantifying endogenous mediators by microdialysis and liquid and/or gas chromatography mass spectrometry and indirectly by site-specific administration of pharmacological agents that regulate endocannabinoid uptake or degradation.

\section{CANNABINOID-INDUCED SUPPRESSION OF NOCICEPTIVE TRANSMISSION}

Electrophysiological and neurochemical studies provide convincing evidence that cannabinoids suppress nociceptive transmission in vivo. ${ }^{82-90}$ Walker's laboratory first demonstrated that cannabinoids suppress noxious stimulus-evoked neuronal activity in nociceptive neurons in the spinal cord and thalamus. ${ }^{84,85,88,91,92}$ This suppression is observed in nociceptive neurons, generalizes to different modalities of noxious stimulation (mechanical, thermal, chemical), is mediated by cannabinoid receptors, and correlates with the antinociceptive effects of cannabinoids. ${ }^{84-86,88,91}$ Cannabinoids also suppress $\mathrm{C}$-fiber-evoked responses in spinal dorsal horn neurons recorded in normal, inflamed, and nerve-injured rats. ${ }^{82,87,90,93}$ In addition, cannabinoids suppress spinal Fos protein expression, a neurochemical marker of sustained neuronal activation, ${ }^{94}$ in a variety of animal models of persistent pain $28,91,92,95-98$ through $\mathrm{CB}_{1}$ - and $\mathrm{CB}_{2}$ selective mechanisms. Most electrophysiological studies have focused on wide-dynamic-range and nociceptivespecific cells recorded at the level of the spinal dorsal horn and have provided convincing evidence that cannabinoids suppress the transmission of nociceptive information. In vivo electrophysiological studies of brainstem neurons implicated in the descending control of pain have also provided insight into the role of cannabinoids in pain modulation and will be discussed below. ${ }^{89,99}$

\section{CANNABINOID ANTINOCICEPTIVE EFFICACY IN Tissue InJURy Models OF Persistent Pain}

Studies using systemic administration of cannabinoids have demonstrated antinociception in multiple models of inflammatory nociception. Kosersky et $\mathrm{al}^{78}$ showed that systemic
$\Delta^{9}$-THC increases the threshold for paw pressure-induced vocalization following the induction of inflammation in the hind paw. Tsou et $\mathrm{al}^{92}$ used the formalin test to show that systemic cannabinoids suppress noxious stimulus-evoked Fos protein expression and pain-related behaviors. The formalin test assesses supraspinally organized pain behavior. Our laboratory demonstrated that neurotoxic destruction of descending noradrenergic projections to the spinal cord reduces the suppression of formalin-evoked Fos protein expression induced by WIN55212-2. ${ }^{100}$ The contribution of peripheral and spinal sites of action to cannabinoid antinociception in tissue and nerve injury models of persistent pain is now well documented (for review, see Hohmann ${ }^{20}$ ). By contrast, the contribution of supraspinal sites to cannabinoid analgesic action in models of persistent pain has received less attention.

\section{CANNABINOID ANTINOCICEPTIVE EFFICACY IN Nerve InJURy Models Of PERsistent PAIN}

Antihyperalgesic and antiallodynic efficacy of cannabinoids has been demonstrated in several rodent models of experimental neuropathy. Bennett's group demonstrated antihyperalgesic and antiallodynic efficacy of a cannabinoid following a chronic constriction injury of the sciatic nerve. ${ }^{101}$ The changes were blocked by systemic administration of a $\mathrm{CB}_{1}$ antagonist. ${ }^{101}$ Hyperalgesia and allodynia induced by tight ligation of the L5 spinal nerve is also attenuated by systemic administration of WIN55212-2; these effects were reversed by a $\mathrm{CB}_{1}$ but not by a $\mathrm{CB}_{2}$ antagonist. ${ }^{102}$ Cannabinoidinduced antinociception remains effective in nerve-injured rats following repeated administration, suggesting that cannabinoids are superior to opioids in alleviating neuropathic pain. ${ }^{103}$ The existence of a substantial population of spinal cannabinoid receptors that remain intact following rhizotomy $^{86,104}$ may have clinical relevance, especially for deafferentation pain that is refractory to treatment with conventional narcotic analgesics. ${ }^{105}$ The experimental studies thereby support the idea that the cannabinoids have a novel therapeutic target in treating neuropathic pain.

One possible mechanism for the antihyperalgesic actions of cannabinoids in neuropathic pain is suggested by cannabinoid-induced suppression of windup and noxious stimulus-induced central sensitization. ${ }^{90,106}$ Support for the idea that there are both central and peripheral sites of cannabinoid antihyperalgesic efficacy has recently been demonstrated in a rat model of neuropathy using intrathecal and intraplantar administration of cannabinoid agonists and antagonists. ${ }^{107}$ Electrophysiological studies also provide evidence for plasticity of the spinal cannabinoid system following tight ligation of the L5/L6 spinal nerve. Plasticity of cannabinoid systems may contribute to cannabinoid therapeutic efficacy in neuropathic pain states. ${ }^{106}$ However, less is known 


\section{The AAPS Journal 2006; 8 (4) Article 79 (http://www.aapsj.org).}

about the possible contribution of supraspinal sites of cannabinoid analgesic action to the control of neuropathic pain.

The nucleus reticularis gigantocellularis pars alpha is implicated in cannabinoid modulation of neuropathic pain. ${ }^{108}$ In rats subjected to partial sciatic nerve ligation (Seltzer model), unilateral hind paw injections of formalin contralateral to the site of nerve damage showed a reduced behavioral response to formalin compared with control conditions in the absence of nerve injury. ${ }^{108}$ Administration of rimonabant to the nucleus reticularis gigantocellularis pars alpha of nerve-injured rats increased behavioral responses to formalin. ${ }^{108}$ Although these data are consistent with the hypothesis that nerve injury activates $\mathrm{CB}_{1}$-mediated endogenous antinociceptive mechanisms from the nucleus reticularis gigantocellularis pars alpha in the formalin test, inverse agonist effects ${ }^{109}$ can complicate interpretation of studies employing rimonabant to evaluate endogenous cannabinoid tone. ${ }^{90,110}$ Further work is necessary to determine whether endocannabinoids mediate the observed effects and to identify a physiological role for a specific endocannabinoid in this effect.

\section{SUPRASPINAL SITES IMPLICATED IN CANnAbinoid Modulation OF PaIN}

Direct support for the notion that there are supraspinal sites of cannabinoid antinociception was initially revealed in studies assessing acute withdrawal responses to thermal stimulation. The antinociceptive ${ }^{111}$ effects of $\Delta^{9}$-THC in the tail-flick test are attenuated following spinal transection, providing indirect evidence that supraspinal sites play an important role in cannabinoid antinociceptive action. Electrophysiological studies ${ }^{86}$ similarly suggest that the suppressive effects of systemically administered cannabinoids on noxious stimulus-evoked responses in spinal nociceptive neurons are attenuated following spinal transection. Direct evidence for supraspinal sites of cannabinoid analgesic action was derived from the observation that intraventricular administration of cannabinoids WIN55212-2, CP55940, and $\Delta^{9}$-THC induces antinociception. ${ }^{12,113}$ Consistent with these behavioral studies, intraventricular administration of WIN55212-2 also suppresses noxious stimulus-evoked responding in wide-dynamic-range neurons recorded in the spinal dorsal horn. ${ }^{86}$ Using autoradiographic methods, a study employing intraventricular administration of $\left[{ }^{3} \mathrm{H}\right]$ WIN55212-2 confirmed that the radiolabeled drug was confined to periventricular sites throughout the brain. These studies underscore the importance of periventricular structures in contributing to cannabinoid-mediated pain modulation.

Site-specific injections of cannabinoid agonists to various brainstem regions have been used to identify supraspinal sites of cannabinoid antinociception. Using the tail-flick test, additional studies demonstrated that microinjection of cannabinoids into sites such as the dorsolateral PAG, dorsal raphe nucleus, RVM, amygdala, lateral posterior and submedius regions of the thalamus, superior colliculus, and noradrenergic A5 region produces antinociception. ${ }^{114-116}$ Lichtman et al demonstrated that administration of CP55940 in the vicinity of the posterior ventrolateral PAG/dorsal raphe also produced antinociception, catalepsy, and hypothermia that was selective for the active stereoisomer. ${ }^{113}$ By contrast, administration of CP55940 to the caudate putamen produced catalepsy but failed to induce antinociception or hypothermia. Microinjection of the cannabinoid HU210 into the dorsal PAG also produces a $\mathrm{CB}_{1}$-mediated suppression of formalin-evoked nocifensive behavior and attenuates formalin-evoked Fos protein in the caudal lateral PAG. ${ }^{98}$ The intra-PAG injection of the cannabinoid also attenuated aversive defense behavior (ie, locomotor activation) elicited by dorsal PAG injections of the excitatory amino acid D,L-homocysteic acid. ${ }^{98}$ Exogenous cannabinoids also modulate ultrasound-induced aversive responses in rats through actions in the dorsal PAG, although these effects were insensitive to blockade by rimonabant. ${ }^{117}$ These studies provide support for the hypothesis that endocannabinoids may modulate pain and defense behaviors through actions in the PAG.

While the studies described above identify sites where exogenously administered synthetic cannabinoids induce antinociception, they do not elucidate which endocannabinoids play a role in pain modulation. Investigators commonly hypothesize the role of a particular endocannabinoid from data showing that the compound induces antinociception. This method assumes that appropriate stimulation conditions result in the in vivo release of the endocannabinoid and that the compound's net effect is sufficient to suppress pain sensitivity. In other studies, investigators correlate endocannabinoid levels or release, and the observation of antinociception. This method is informative but incapable of establishing causation. With these limitations in mind, the following sections review what is known about the role of particular endocannabinoids in nociceptive responding.

\section{PAG}

The PAG is a common neural substrate underlying both analgesia and aversive responses. Electrical stimulation of the PAG produces analgesia and defensive behavior ${ }^{118,119}$ that depends upon the activation of specific subdivisions of the nucleus. Electrical stimulation of the ventrolateral PAG produces analgesia that is blocked by opioid antagonists such as naltrexone, ${ }^{118}$ suggesting that there is mediation by endogenous opioid peptides. By contrast, electrical stimulation of the dorsal and lateral PAG produces analgesia that is insensitive to blockade by opioid antagonists, ${ }^{118}$ mediated 


\section{The AAPS Journal 2006; 8 (4) Article 79 (http://www.aapsj.org).}

by endocannabinoids, and blocked by cannabinoid antagonists. ${ }^{120}$ Walker's group showed that electrical stimulation of the dorsal and lateral PAG resulted in cannabinoid receptormediated stimulation-produced analgesia concurrent with the mobilization of anandamide. ${ }^{120}$ These actions were blocked by systemic or intra-PAG microinjection of rimonabant, consistent with mediation by $\mathrm{CB}_{1}$. We recently demonstrated that 2-AG and anandamide are elevated in dorsal midbrain fragments containing the entire PAG concomitantly with the expression of nonopioid stress-induced analgesia (SIA). We showed that exposure to a 3-minute continuous foot shock induced a $\mathrm{CB}_{1}$-mediated SIA independent of endogenous opioids. ${ }^{52}$ Moreover, microinjection of FAAH inhibitors such as URB59752 and arachidonoylserotonin ${ }^{121}$ also enhanced SIA in a $\mathrm{CB}_{1}$-dependent manner. Microinjection of the MGL inhibitor URB602 into the PAG also induced a $\mathrm{CB}_{1}$-mediated enhancement of stress antinociception and selectively elevated levels of 2-AG (but not anandamide) in this region. ${ }^{52}$ These data identify a physiological role for endogenous 2-AG in pain modulation at the level of the midbrain PAG.

Not all effects of endocannabinoids are mediated by $\mathrm{CB}_{1}$ receptors, and therefore, it is important to demonstrate that endocannabinoid actions are blocked by selective cannabinoid antagonists. Microinjection of the FAAH inhibitor URB597 into the ventrolateral PAG has been reported to elevate endocannabinoids (both anandamide and 2-AG) and induce biphasic effects on thermal nociception via activation of $\mathrm{CB}_{1}$ and TRPV1 receptor mechanisms. ${ }^{99}$ In this study, the TRPV1-mediated antinociception and $\mathrm{CB}_{1}$ mediated nociception caused by URB597 correlated with enhanced or reduced activity of RVM off-cells, suggesting that these effects occur via stimulation or inhibition of excitatory PAG output neurons, respectively. ${ }^{99}$ At the highest dose tested, however, URB597 (4 nmol/rat) and WIN552122 (25-100 nmol) caused only $\mathrm{CB}_{1}$-mediated analgesia, correlating with stimulation (possibly disinhibition) of RVM off-cells. ${ }^{99}$ Thus, anandamide but not 2-AG may affect the descending pathways of pain control by acting at either $\mathrm{CB}_{1}$ or TRPV1 receptors in select PAG subregions. ${ }^{99}$

In vitro electrophysiological studies indicate that cannabinoids inhibit both gamma-aminobutyric acid-ergic (GABAergic) and glutamatergic synaptic transmission presynaptically in rat PAG through a $\mathrm{CB}_{1}$-specific mechanism. ${ }^{122}$ The cellular actions of cannabinoids are distinct from those of mu opioids because cannabinoids lack direct postsynaptic action on PAG neurons. Exogenous cannabinoids are likely to reduce the probability of transmitter release from presynaptic terminals via a $\mathrm{Ca}^{2+}$-independent mechanism, ${ }^{122}$ suggesting that endocannabinoids behave similarly under physiological conditions.

Metabotropic glutamate and $N$-methyl-D-aspartic acid (NMDA) receptors are required for cannabinoid antinoci- ception at the level of the PAG. ${ }^{123}$ Infusion of WIN55212-2 into the PAG produced dose-dependent increases in paw withdrawal latencies in the plantar test. ${ }^{123}$ This antinociceptive effect was blocked by pretreatment with rimonabant, which at high doses also produced modest hyperalgesia. Blockade of mGlu5 metabotropic glutamate receptors but not mGlu1 receptors completely blocked the effects of WIN55212-2. Both mGlu5 and mGlu1 receptors belong to the group I class of metabotropic glutamate receptors, which are G-protein-coupled and positively coupled to phospholipase C. Pretreatment with antagonists for group II (which includes mGlu2 and mGlu3) and group III (which includes mGlu4, mGlu6, mGlu7, and mGlu8) metabotropic glutamate receptors, which are negatively coupled to adenylate cyclase and preferentially localized to presynaptic active zones associated with autoreceptors, also suppressed WIN55212-2-induced antinociception. In addition to these metabotropic glutamate receptors, a selective antagonist for ionotropic glutamate (NMDA) receptors also blocked the antinociceptive effects of WIN55212-2. More work is necessary to elucidate the role of metabotropic glutamate receptors in endocannabinoid mechanisms of pain suppression.

\section{RVM}

Researchers have targeted synthetic cannabinoids at other brainstem nuclei such as the RVM ${ }^{108,116,124}$ and the nucleus reticularis gigantocellularis ${ }^{108}$ to better characterize sites of cannabinoid-mediated antinociception. Walker's group demonstrated that site-specific administration of cannabinoids (WIN55212-2 and HU210) in the RVM produced antinociception in the tail-flick test. ${ }^{116}$ Mediation by $\mathrm{CB}_{1}$ receptors was evident because the antinociceptive effects of HU210 were blocked by rimonabant and the receptorinactive enantiomer WIN55212-3 failed to induce antinociception following microinjection to the same site. ${ }^{116}$

Electrophysiological studies have provided functional insight into the mechanism mediating these antinociceptive effects. In vivo recordings provide direct evidence that cannabinoids modulate on- and off-cells in the RVM, ${ }^{89,125}$ thereby demonstrating the ability of these ligands to control descending pain modulatory signaling via a process similar to that of morphine. In lightly anesthetized rats, on-cells exhibit a burst of activity before the tail-flick nociceptive reflex, enhancing nociceptive transmission, whereas offcells show a suppression of firing before the tail-flick reflex, inhibiting nociceptive transmission. Cannabinoids increased ongoing off-cell activity and reduced both the off-cell pause as well as the on-cell burst that occurs just prior to the tailflick reflex. These actions were mediated by a $\mathrm{CB}_{1}$ mechanism that is not dependent upon endogenous opioids. ${ }^{89}$ Pharmacological inactivation of the RVM with site-specific administration of the $\mathrm{GABA}_{\mathrm{A}}$ receptor agonist muscimol 


\section{The AAPS Journal 2006; 8 (4) Article 79 (http://www.aapsj.org).}

also blocked the antinociceptive effects but not the motor deficits of systemically administered WIN55212-2. ${ }^{89}$ This work identifies a GABAergic link in cannabinoid antinociceptive mechanisms. At the cellular level, cannabinoids exert their physiological effects in the RVM by presynaptic inhibition of GABAergic neurotransmission. ${ }^{124}$ Collectively, these results suggest that nociceptive responsiveness is modulated in the RVM by endocannabinoids, although the specific endocannabinoids mediating these actions remain to be identified.

The nucleus reticularis gigantocellularis pars alpha within the RVM represents a major source of descending control induced by cannabinoids and is also directly activated by noxious stimulation. Microinjection of WIN55212-2 to the nucleus gigantocellularis pars alpha produced antinociception in the tail flick and formalin tests in otherwise untreated rats. ${ }^{108}$ These effects were blocked by a $\mathrm{CB}_{1}$ antagonist. Microdialysis studies coupled with high-performance liquid chromatography mass spectrometry, together with sitespecific administration of inhibitors of endocannabinoid degradation and synthesis, would be particularly useful in identifying which endocannabinoids mediate these effects.

\section{ROLE OF THE AMYGDALA}

The amygdala consists of a nuclear complex located in the limbic forebrain and plays a key role in the coordination of fear and defensive reactions. The amygdala is optimally positioned anatomically to receive and integrate sensory information from multiple modalities and, in turn, to mediate emotional, autonomic, and somatic motor reactions to salient stimuli (especially threatening stimuli). ${ }^{126}$ Within the amygdala, $\mathrm{CB}_{1}$ immunoreactivity has been detected in a subset of GABAergic interneurons in the basolateral complex, ${ }^{127}$ a site implicated in the formation and storage of aversive memories. ${ }^{128}$ Anandamide and 2-AG are elevated in the basolateral amygdala in a conditioned fear aversion paradigm, ${ }^{127}$ supporting the hypothesis that endocannabinoids serve naturally to inhibit extinction of aversive memories. Endocannabinoids and $\mathrm{CB}_{1}$ receptors in the basolateral nucleus of the amygdala are implicated in the long-term depression of GABAergic inhibitory currents, suggesting that endocannabinoids regulate aversive memory extinction via selective inhibition of local inhibitory networks in the amygdala. ${ }^{127}$

The amygdala also plays a critical role in modulating antinociception. Microinjection of cannabinoids into the basolateral nucleus of the amygdala produces antinociception in the tail-flick test. ${ }^{96}$ Microinjection of $\mu$ opioid agonists into the basolateral nucleus of the amygdala similarly results in marked antinociceptive responding in the radiant heat tailflick ${ }^{129,130}$ and formalin tests. ${ }^{131}$ Moreover, bilateral lesions of the amygdala rendered nonhuman primates less sensitive to the antinociceptive effects of the potent synthetic cannabinoid WIN55212-2.132 In rodents, microinjection of the $\mathrm{GABA}_{\mathrm{A}}$ agonist muscimol into the central nucleus of the amygdala, but not into the basolateral nucleus of the amygdala, reduced the antinociceptive effects of systemic WIN55212-2. ${ }^{133}$ Moreover, FAAH and MGL are localized to postsynaptic and presynaptic sites, respectively, in the basolateral and lateral amygdala. ${ }^{53,55,59}$ These data indicate that mechanisms exist for deactivation of anandamide and $2-A G$ in the basolateral amygdala. Both conditioned ${ }^{134,135}$ and unconditioned ${ }^{136}$ SIA depend on intact functioning of the amygdala. These observations, together with the demonstration of cannabinoid-mediated antinociceptive effects following site-specific administration to the basolateral nucleus of the amygdala, ${ }^{114}$ suggest that endocannabinoids may serve naturally to suppress environmentally induced pain by actions in the amygdala. Below, we provide evidence that endocannabinoids may specifically mediate antinociceptive effects induced by exposure to environmental stressors, through actions in the PAG and to a lesser extent in the RVM and spinal cord.

\section{BEHAVIORAL EVIDENCE FOR A ROLE OF ENDOCANNABINOIDS IN SIA}

Stress activates neural systems that suppress pain sensation. This adaptive response is known as SIA and depends on the recruitment of brain pathways that project from the amygdala to the midbrain PAG and descend to the brainstem RVM and dorsal horn of the spinal cord (for review, see Walker and Hohmann ${ }^{21}$ ). For years, it has been recognized that endogenous opioid peptides participate in this process, ${ }^{137,138}$ but the inability of opioid antagonists to block stress antinociception elicited by distinct stressor parameters made it clear that other unidentified mechanisms were also involved.

We hypothesized that endocannabinoids might mediate nonopioid SIA induced by brief, continuous foot shock. ${ }^{52}$ First, agonists of $\mathrm{CB}_{1}$ receptors - the predominant cannabinoid receptor subtype present in the brain ${ }^{2,7}$ - exert profound antinociceptive effects ${ }^{21}$ and suppress activity in nociceptive neurons. ${ }^{84,86,88,89}$ Second, $\mathrm{CB}_{1}$ antagonists increase the activity of nociceptive RVM neurons ${ }^{89}$ and enhance sensitivity to noxious stimuli, ${ }^{23}$ which suggests that an intrinsic endocannabinoid tone regulates descending antinociceptive pathways. ${ }^{21}$

We quantified the poststress sensitivity to pain in rats using the tail-flick test after exposure to a 3-minute foot shock stressor. ${ }^{52}$ As demonstrated previously, ${ }^{138,139}$ this stimulation protocol caused a profound antinociceptive effect that was not altered by systemic injection of the opiate antagonist naltrexone but was virtually eliminated by systemic administration of the competitive $\mathrm{CB}_{1}$ receptor antagonists/ 
inverse agonists rimonabant and AM251. Moreover, in rats rendered tolerant to the antinociceptive effects of cannabinoids (by daily treatment with WIN55212-2 for 14 days) a marked attenuation in stress antinociception was observed. ${ }^{52}$ It was unlikely that this change was due to altered opioid tone, because cannabinoid-tolerant rats showed no changes in antinociceptive responsiveness to morphine and rats tolerant to morphine showed no attenuation of nonopioid stress antinociception. ${ }^{52}$

Pharmacological blockade of TRPV1 via systemic administration of capsazepine also failed to alter stress analgesia in our testing paradigm, ${ }^{121}$ suggesting that endocannabinoidmediated stress analgesia was not dependent on TRPV1. The same dose of capsazepine that failed to affect endocannabinoid-mediated stress antinociception, however, reliably reduced capsaicin-induced antinociception in the tail-flick test. ${ }^{121}$

We reasoned that if endocannabinoid activation of $\mathrm{CB}_{1}$ receptors mediates nonopioid SIA, then inhibition of endocannabinoid deactivation should enhance stress antinociception. To test this hypothesis, we administered FAAH inhibitors (URB597, arachidonoyl serotonin, or palmitoyl trifluoromethyl ketone) to rats and examined the resultant stress-induced antinociception in the tail-flick assay. ${ }^{52,121}$ Regardless of the pharmacological method used to inhibit FAAH, postshock SIA was enhanced in animals treated systemically with FAAH inhibitors. In all cases, these effects were blocked by rimonabant, consistent with a $\mathrm{CB}_{1-}{ }^{-}$ dependent mechanism of action. ${ }^{52,121}$ Systemic administration of rimonabant also attenuates fear-conditioned antinociceptive responses in the formalin test, together with freezing behavior and defecation, suggesting that $\mathrm{CB}_{1}$ receptors and endocannabinoids may also contribute to fearconditioned analgesia. ${ }^{140}$

\section{SITES OF ACTION OF ENDOCANNABINOID- MEDiATED SIA}

To further investigate the sites of action of endocannabinoids in mediating stress antinociception, we microinjected rimonabant at multiple levels of the neuraxis and quantified poststress sensitivity to pain in rats using the tail-flick test. We targeted brain structures involved in pain and stress responsiveness that contain $\mathrm{CB}_{1}$ receptors and are implicated in cannabinoid antinociception, including the dorsolateral PAG, ventral PAG, RVM, basolateral nucleus of the amygdala, central nucleus of the amygdala, and lumbar spinal cord. ${ }^{52,121,141}$ Rimonabant microinjection into the dorsolateral PAG produced the greatest suppression of SIA relative to all other sites surveyed (Figure 3 and data not shown). These findings are consistent with the presence of $\mathrm{CB}_{1}$ receptors in the PAG and suggest that this structure plays a pivotal role in nonopioid SIA.

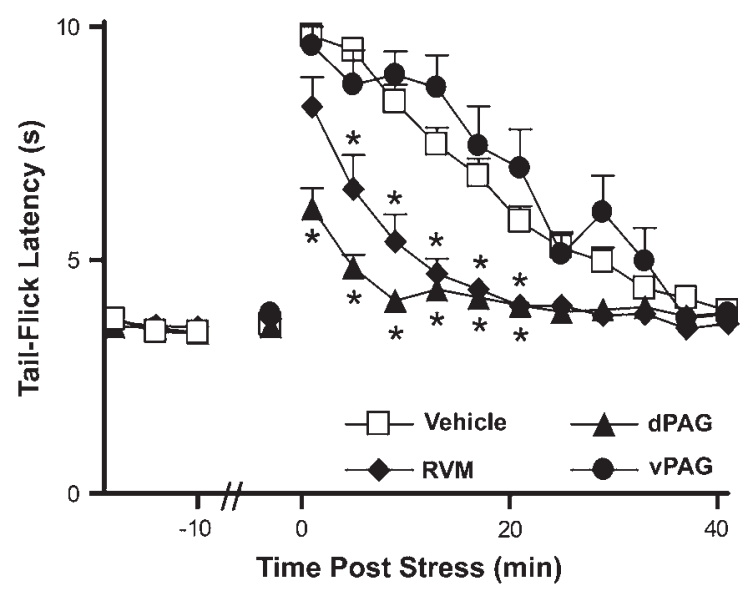

Figure 3. The dPAG plays a pivotal role in nonopioid stressinduced analgesia. Rimonabant $(2 \mathrm{nmol})$ microinjection into the dPAG induced a maximal suppression of stress antinociception $\left(\mathrm{F}_{3,484}=96.42, P<.0001\right)$ relative to the vPAG, the RVM, or control conditions. SIA was assessed as the postshock $(0.9 \mathrm{~mA}$ for 3 minutes) tail-flick latency by an investigator blinded to the experimental condition. Vehicle groups did not differ from each other and were pooled for all sites. ${ }^{52,121} \mathrm{dPAG}$ indicates dorsolateral PAG; RVM, rostral ventromedial medulla; SIA, stress-induced analgesia; and vPAG, ventrolateral PAG.

\section{STRESS MOBILIZES ENDOCANNABINOIDS TO SUPPRESS PAIN}

To determine whether endocannabinoid release is involved in SIA, we measured anandamide and 2-AG levels in dorsal midbrain fragments (containing the intact PAG) of rats killed without exposure to or at various times after foot shock. ${ }^{52}$ Liquid chromatography/mass spectrometry (LC/MS) analyses revealed that midbrain 2-AG levels were markedly increased 2 minutes after shock and returned to baseline $\approx 15$ minutes later. This response preceded a sustained increase in anandamide levels, which peaked 7 to 15 minutes following the shock. No such changes were observed in the occipital cortex, a brain region that contains $\mathrm{CB}_{1}$ receptors but is not considered part of the SIA circuit. The rapid poststress accumulation of 2-AG in the PAG suggests that endocannabinoid release, rather than intrinsic $\mathrm{CB}_{1}$ activity, is responsible for SIA.

We compared the time courses of endocannabinoid mobilization in the PAG with those of SIA. A strong temporal correspondence was found between these parameters ( $\mathrm{r}=$ $0.943, P<.03$ ), consistent with mediation by a common mechanism (Figure 4). By contrast, anandamide was released with a strikingly dissimilar time course that does not closely correspond to that of 2-AG mobilization or SIA over the same interval $(\mathrm{r}=-0.479, P=.26)$. This temporal correlation points to $2-\mathrm{AG}$ as a key mediator of nonopioid SIA. 
The AAPS Journal 2006; 8 (4) Article 79 (http://www.aapsj.org).
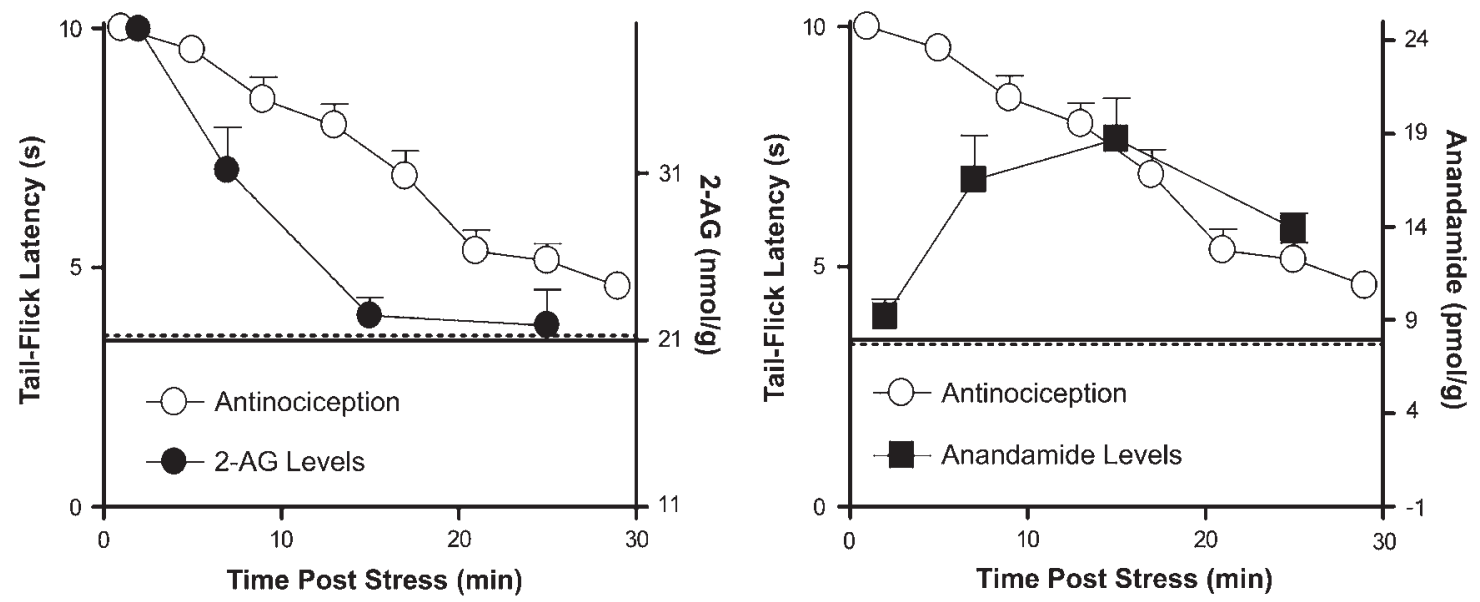

Figure 4. Stress antinociception shows a temporal correspondence with 2-AG accumulation in midbrain periaqueductal gray. A significant correlation was observed between 2-AG $(r=0.943, P<.03)$ but not anandamide $(r=-0.479, P=.26)$ accumulation and stress antinociception over the same time course. Stress antinociception was assessed as the postshock ( $0.9 \mathrm{~mA}$ for 3 minutes) tail-flick latency. (-) basal nociceptive threshold; (-) basal endocannabinoid level. ${ }^{52}$ 2-AG indicates 2-arachidonoylglycerol.

\section{ENDOGENOUS 2-AG MEdiates SIA}

If mobilization of 2-AG in the PAG mediates SIA, selective inhibitors of MGL should increase accumulation of 2-AG and enhance SIA. ${ }^{52}$ Consistent with this prediction, microinjection of the novel MGL inhibitor URB602 into the dorsolateral PAG or ventrolateral PAG enhanced SIA. ${ }^{52}$ Basal nociceptive thresholds in nonshocked rats were unaffected. The effect of URB602 was likely due to the accumulation of 2-AG in the PAG because the URB602-mediated enhancement of SIA was prevented by coadministration of rimonabant and accompanied by an elevation in midbrain 2-AG levels. ${ }^{52}$ Microinjection of URB602 into the PAG increased accumulation of 2-AG in brains of rats exposed to the stressor relative to vehicle-treated controls without altering levels of anandamide. These findings indicate that the MGL inhibitor URB602 enhances both 2-AG accumulation and SIA. These studies suggest that endogenous 2-AG plays a physiological role in pain modulation.

\section{SITE-SPECIFIC ENHANCEMENT OF ENDOCANNABINOID DEACTIVATION ENHANCES STRESS ANTINOCICEPTION}

Because the PAG serves key functions in both the descending control of pain ${ }^{21,120}$ and the antinociceptive actions of cannabinoid agonists, ${ }^{115}$ we examined the impact on stress antinociception of pharmacologically manipulating endocannabinoid deactivation using site-specific microinjections. Microinjection of either the FAAH inhibitor URB59752 or arachidonoyl serotonin ${ }^{121}$ to the dorsolateral PAG enhanced the magnitude and duration of endocannabinoid-mediated stress antinociception. These effects were blocked by coadministration of rimonabant, at a dose that was insufficient to reverse stress antinociception. It has recently been reported that site-specific microinjections of URB597 into the ventrolateral PAG enhance nociceptive behavior assessed in the plantar and tail-flick tests in otherwise naive rats, ${ }^{99}$ despite producing enhanced anandamide and 2-AG levels. Consistent with our results, however, the highest dose of URB597 tested produced $\mathrm{CB}_{1}$-mediated antinociception.

Cannabinoids microinjected into neural targets of the PAG in the RVM induce antinociception and suppress nociceptive processing. ${ }^{98,116,125}$ Like opioids, ${ }^{142}$ cannabinoids modulate on- and off-cells in the RVM ${ }^{89}$ demonstrating the ability of these ligands to control descending pain signaling. Based upon the anatomy of the midbrain-to-brainstem pain modulation circuit and upon the robust effects of blocking $\mathrm{CB}_{1}$ receptors in the dorsolateral PAG or RVM in attenuating SIA, ${ }^{52}$ we further reasoned that inhibition of endocannabinoid deactivation at the level of the RVM would enhance stress antinociception. ${ }^{121}$ Pharmacological inhibition of FAAH via site-specific microinjections of arachidonoyl serotonin into the RVM enhanced stress antinociception via a $\mathrm{CB}_{1}$-specific mechanism. ${ }^{121}$

In rats, spinal transection reduces the antinociceptive $\mathrm{e}^{111}$ and electrophysiological ${ }^{86}$ effects of cannabinoids. However, an enduring residual antinociception remains in spinally transected mice, ${ }^{143}$ suggesting that endocannabinoids exert an analgesic effect at the spinal level as well as supraspinally. The localization of $\mathrm{CB}_{1}$ receptors in the spinal dorsal horn ${ }^{7,104}$ supports this view. Exogenously administered cannabinoids also produce antinociception when applied directly to the spinal cord ${ }^{96,143-146}$ and suppress noxious stimulus-evoked neuronal activity in spinal nociceptive neurons, ${ }^{82,85-87}$ suggesting that spinal cannabinoid receptors have a functional role in modulating nociceptive processing. Intrathecal administration of either rimonabant or $\mathrm{CB}_{1}$ antisense oligonucleotides also elicits hyperalgesia, ${ }^{147}$ 


\section{The AAPS Journal 2006; 8 (4) Article 79 (http://www.aapsj.org).}

suggesting that endocannabinoids may act tonically to suppress nociceptive responding.

To identify a physiological role for endocannabinoids at the spinal level, we bidirectionally manipulated endocannabinoid tone at $\mathrm{CB}_{1}$ receptors in the lumbar spinal cord and assessed endocannabinoid mobilization in the lumbar spinal cord following exposure to a 3-minute continuous foot shock. ${ }^{141}$ Stress antinociception was associated with the heightened release of endogenous 2-AG, whereas increases in anandamide mobilization were not detected, ${ }^{141}$ perhaps because of greater variability and lower absolute levels of anandamide in these samples. Rimonabant failed to suppress endocannabinoid SIA when administered intrathecally to rats at a dose 10 times greater than that delivered to the PAG and RVM. ${ }^{141}$ Nonetheless, pharmacological inhibitors of FAAH and MGL markedly enhanced the magnitude and duration of stress antinociception after intrathecal administration via a $\mathrm{CB}_{1}$-specific mechanism. ${ }^{141}$ Our results show that, at the level of the spinal cord, endocannabinoids regulate but do not mediate nonopioid SIA.

The activity of endocannabinoids in the descending neural pathway projecting from the PAG to the RVM to the spinal cord is implicated in the activation of endogenous pain suppression mechanisms in response to stress. We also examined neuroanatomically "upstream" centers responsible for activating this mechanism following exposure to a stressor. Situated in the limbic forebrain, the amygdala is implicated in both fear conditioning ${ }^{148}$ and the affective ${ }^{133,149}$ dimensions of pain. $\mathrm{CB}_{1}$ immunoreactivity is dense in the basolateral nucleus of the amygdala (BLA) ${ }^{2,150}$ but is reportedly absent in the central nucleus of the amygdala (CeA). ${ }^{150}$ The anatomical localization of $\mathrm{CB}_{1}$ in the $\mathrm{BLA}$ is consistent with electrophysiological data demonstrating that activation of these receptors presynaptically modulates GABAergic transmission. ${ }^{150}$ The distribution of FAAH and MGL at this site also correlates well with the distribution of $\mathrm{CB}_{1}$ receptors. ${ }^{59} \mathrm{BLA}$ efferents innervate the $\mathrm{CeA}$, the main amygdaloid output nucleus, which sends projections to the PAG and other regions. Unilateral microinjection of cannabinoid agonists into the amygdala also induces antinociception in the tail-flick test, ${ }^{114}$ supporting the notion that this structure plays a role in modulation of pain sensitivity.

Microinjections of rimonabant into the BLA, but not the CeA, suppressed nonopioid stress antinociception in our paradigm. ${ }^{151}$ Our data are consistent with the observation that $\mathrm{CB}_{1}$ agonists depress monosynaptic evoked inhibitory postsynaptic potentials in the BLA but not in the CeA. ${ }^{150}$ Our results, therefore, suggest that $\mathrm{CB}_{1}$ receptors in the BLA modulate local inhibitory networks in the BLA to ultimately regulate expression of SIA. Nonetheless, neither the FAAH inhibitor URB597 nor the MGL inhibitor URB602 enhanced SIA following $\mathrm{v}$ into the BLA ${ }^{151}$ at doses that markedly potentiated SIA following microinjection into the midbrain dorsolateral PAG. ${ }^{52}$ These differences may reflect differential modulatory roles of distinct endocannabinoids in the ascending "affective" pain pathway compared with descending pain modulatory systems, or higher hydrolytic activity of endocannabinoid-degrading enzymes in the BLA relative to the PAG.

In sum, our results suggest that the coordinated release of 2-AG and anandamide in the PAG, RVM, and lumbar spinal cord mediates nonopioid SIA. The 2 endocannabinoids may act on local $\mathrm{CB}_{1}$ receptors ${ }^{2,7,122}$ to regulate glutamatergic and GABAergic transmission, ultimately disinhibiting descending pain control pathways. Three points are worthy of emphasis. ${ }^{52}$ First, endocannabinoid-dependent stress antinociception is not affected by opioid antagonists or morphine tolerance, which implies that it may not require opioid activity. However, mutant $\mathrm{CB}_{1}$ null mice also display reduced opioid-mediated responses to stress, ${ }^{152}$ so opioid SIA need not be independent of endocannabinoids. Second, the residual antinociception observed in the presence of $\mathrm{CB}_{1}$ antagonists leaves open the possibility that additional mediators of nonopioid SIA remain to be discovered. Third, stress mobilizes both 2-AG and anandamide in the dorsal midbrain, but these 2 endocannabinoids are released with distinctly dissimilar time courses. This observation underscores the existence of functional differences between these signaling molecules ${ }^{36}$ that may be relevant to understanding endocannabinoid actions in other brain regions. The ability of both MGL and FAAH inhibitors to enhance endocannabinoiddependent stress antinociception also highlights the significance of these enzymes as novel targets for the treatment of pain and stress- and anxiety-related disorders. ${ }^{52,68}$

\section{CONCLUSIONS}

Interest in the behavioral effects of cannabinoids has burgeoned since the cloning of cannabinoid $\mathrm{CB}_{1}$ and $\mathrm{CB}_{2}$ receptors and the isolation of endocannabinoids. The ability of cannabinoids to induce antinociception in virtually every animal model of acute or persistent pain evaluated has encouraged researchers to try to better understand this important nonopioid system of analgesia. Neuroanatomical studies have revealed that cannabinoid $\mathrm{CB}_{1}$ receptors, endocannabinoids, and endocannabinoid-degrading enzymes are localized in central nervous system regions subserving the transmission and modulation of nociceptive signaling. Behavioral tests of acute nociception and tissue and nerve injury models of nociception have helped confirm the hypothesis that cannabinoids mediate antinociception via activation of $\mathrm{CB}_{1}$ and $\mathrm{CB}_{2}$ receptors. Recent studies have clarified the role of peripheral, spinal, and supraspinal sites in $\mathrm{CB}_{1}$-dependent analgesia.

Cannabinergic agents may offer promise in clinical pain management both on their own and as adjuncts to conventional 
The AAPS Journal 2006; 8 (4) Article 79 (http://www.aapsj.org).

therapeutic agents. Cannabinoids may be particularly efficacious for pain syndromes that are intractable to conventional analgesics (eg, neuropathic pain) $)^{153,154}$ and in patient populations where the emetic effects of opioids are poorly tolerated (eg, cancer patients, AIDS patients). Furthermore, inhibitors of endocannabinoid-degrading enzymes such as FAAH and MGL may function to selectively enhance $\mathrm{CB}_{1^{-}}$ mediated neurotransmission only in nervous system areas where endocannabinoids are synthesized and released on demand, thereby precluding the induction of side effects associated with global $\mathrm{CB}_{1}$ activation. ${ }^{155}$ Moreover, synergism between cannabinoid and opioid analgesia has been demonstrated. ${ }^{144,156}$ Collectively, these findings suggest that activation of cannabinoid receptors and inhibition of endocannabinoid deactivation may be promising targets for the clinical management of pain.

\section{ACKNOWLEDGMENTS}

A.G.H. was supported by DA14265 and DA14022. The authors are grateful to Nathan Bolton of the National Institute on Drug Abuse for his expert technical assistance with the figures.

\section{REFERENCES}

1. Gerard CM, Mollereau C, Vassart G, Parmentier M. Molecular cloning of a human cannabinoid receptor which is also expressed in testis. Biochem J. 1991;279:129-134.

2. Herkenham M, Lynn AB, Johnson MR, Melvin LS, de Costa BR, Rice KC. Characterization and localization of cannabinoid receptors in rat brain: a quantitative in vitro autoradiographic study. J Neurosci. 1991;11:563-583.

3. Matsuda LA, Lolait SJ, Brownstein MJ, Young AC, Bonner TI. Structure of a cannabinoid receptor and functional expression of the cloned cDNA. Nature. 1990;346:561-564.

4. Devane WA, Hanus L, Breuer A, et al. Isolation and structure of a brain constituent that binds to the cannabinoid receptor. Science. 1992;258:1946-1949.

5. Mechoulam R, Ben-Shabat S, Hanus L, et al. Identification of an endogenous 2-monoglyceride, present in canine gut, that binds to cannabinoid receptors. Biochem Pharmacol. 1995;50:83-90.

6. Sugiura T, Kondo S, Sukagawa A, et al. 2-Arachidonoylglycerol: a possible endogenous cannabinoid receptor ligand in brain. Biochem Biophys Res Commun. 1995;215:89-97.

7. Tsou K, Brown S, Sanudo-Peña MC, Mackie K, Walker JM. Immunohistochemical distribution of cannabinoid CB1 receptors in the rat central nervous system. Neuroscience. 1997;83:393-411.

8. Buckley NE, McCoy KL, Mezey E, et al. Immunomodulation by cannabinoids is absent in mice deficient for the cannabinoid $\mathrm{CB}(2)$ receptor. Eur J Pharmacol. 2000;396:141-149.

9. Zimmer A, Zimmer AM, Hohmann AG, Herkenham M, Bonner TI. Increased mortality, hypoactivity, and hypoalgesia in cannabinoid CB1 receptor knockout mice. Proc Natl Acad Sci USA. 1999;96:5780-5785.

10. Galiegue S, Mary S, Marchand J, et al. Expression of central and peripheral cannabinoid receptors in human immune tissues and leukocyte subpopulations. Eur J Biochem. 1995;232:54-61.
11. Munro S, Thomas KL, Abu-Shaar M. Molecular characterization of a peripheral receptor for cannabinoids. Nature. 1993;365:61-65.

12. Schatz AR, Lee M, Condie RB, Pulaski JT, Kaminski NE. Cannabinoid receptors $\mathrm{CB} 1$ and $\mathrm{CB} 2$ : a characterization of expression and adenylate cyclase modulation within the immune system. Toxicol Appl Pharmacol. 1997;142:278-287.

13. Zhang J, Hoffert C, Vu HK, Groblewski T, Ahmad S, O’Donnell D. Induction of CB2 receptor expression in the rat spinal cord of neuropathic but not inflammatory chronic pain models. Eur J Neurosci. 2003; 17:2750-2754.

14. Felder CC, Joyce KE, Briley EM, et al. Comparison of the pharmacology and signal transduction of the human cannabinoid CB1 and CB2 receptors. Mol Pharmacol. 1995;48:443-450.

15. Howlett AC, Qualy JM, Khachatrian LL. Involvement of Gi in the inhibition of adenylate cyclase by cannabimimetic drugs. Mol Pharmacol. 1986;29:307-313.

16. Caulfield MP, Brown DA. Cannabinoid receptor agonists inhibit $\mathrm{Ca}$ current in NG108-15 neuroblastoma cells via a pertussis toxin-sensitive mechanism. Br J Pharmacol. 1992;106:231-232.

17. Mackie K, Hille B. Cannabinoids inhibit N-type calcium channels in neuroblastoma-glioma cells. Proc Natl Acad Sci USA.

1992;89:3825-3829.

18. Mackie K, Lai Y, Westenbroek R, Mitchell R. Cannabinoids activate an inwardly rectifying potassium conductance and inhibit Q-type calcium currents in AtT20 cells transfected with rat brain cannabinoid receptor. J Neurosci. 1995;15:6552-6561.

19. Deadwyler SA, Hampson RE, Mu J, Whyte A, Childers S. Cannabinoids modulate voltage sensitive potassium A-current in hippocampal neurons via a cAMP-dependent process. J Pharmacol Exp Ther. 1995;273:734-743.

20. Hohmann AG. Spinal and peripheral mechanisms of cannabinoid antinociception: behavioral, neurophysiological and neuroanatomical perspectives. Chem Phys Lipids. 2002;121:173-190.

21. Walker JM, Hohmann AG. Cannabinoid mechanisms of pain suppression. In: Pertwee R. ed. Cannabinoids-Handbook of Experimental Pharmacology. Berlin, Germany: Springer; 2005:509-554

22. Malan TP, Jr, Ibrahim MM, Deng H, et al. CB2 cannabinoid receptor-mediated peripheral antinociception. Pain. 2001;93:239-245.

23. Calignano A, La Rana G, Giuffrida A, Piomelli D. Control of pain initiation by endogenous cannabinoids. Nature. 1998;394:277-281.

24. Clayton N, Marshall FH, Bountra C, O'Shaughnessy CT. CB1 and CB2 cannabinoid receptors are implicated in inflammatory pain. Pain. 2002;96:253-260.

25. Hanus L, Breuer A, Tchilibon S, et al. HU-308: a specific agonist for CB(2), a peripheral cannabinoid receptor. Proc Natl Acad Sci USA. 1999;96:14228-14233.

26. Hohmann AG, Farthing JN, Zvonok AM, Makriyannis A. Selective activation of cannabinoid CB2 receptors suppresses hyperalgesia evoked by intradermal capsaicin. J Pharmacol Exp Ther.

2003;308:446-453.

27. Nackley AG, Makriyannis A, Hohmann AG. Selective activation of cannabinoid $\mathrm{CB}_{2}$ receptors suppresses spinal fos protein expression and pain behavior in a rat model of inflammation. Neuroscience. 2003;119:747-757.

28. Nackley AG, 2nd, Suplita RL, 2nd, Hohmann AG. A peripheral cannabinoid mechanism suppresses spinal fos protein expression and pain behavior in a rat model of inflammation. Neuroscience.

2003;117:659-670. 


\section{The AAPS Journal 2006; 8 (4) Article 79 (http://www.aapsj.org).}

29. Quartilho A, Mata HP, Ibrahim MM, et al. Inhibition of inflammatory hyperalgesia by activation of peripheral CB2 cannabinoid receptors. Anesthesiology. 2003;99:955-960.

30. Ibrahim MM, Deng H, Zvonok A, et al. Activation of CB2 cannabinoid receptors by AM1241 inhibits experimental neuropathic pain: pain inhibition by receptors not present in the CNS. Proc Natl Acad Sci USA. 2003;100:10529-10533.

31. Malan TP, Jr, Ibrahim MM, Vanderah TW, Makriyannis A, Porreca F. Inhibition of pain responses by activation of CB2 cannabinoid receptors. Chem Phys Lipids. 2002;121:191-200.

32. Rice AS, Farquhar-Smith WP, Nagy I. Endocannabinoids and pain: spinal and peripheral analgesia in inflammation and neuropathy. Prostaglandins Leukot Essent Fatty Acids. 2002;66:243-256.

33. Walker JM, Huang SM. Endocannabinoids in pain modulation. Prostaglandins Leukot Essent Fatty Acids. 2002;66:235-242.

34. Walker JM, Strangman NM, Huang SM. Cannabinoids and pain. Pain Res Manag. 2001;6:74-79.

35. Stella N, Schweitzer P, Piomelli D. A second endogenous cannabinoid that modulates long-term potentiation. Nature. 1997;388:773-778.

36. Piomelli D. The molecular logic of endocannabinoid signalling. Nat Rev Neurosci. 2003;4:873-884.

37. Gauldie SD, McQueen DS, Pertwee R, Chessell IP. Anandamide activates peripheral nociceptors in normal and arthritic rat knee joints. Br J Pharmacol. 2001;132:617-621.

38. Smart D, Gunthorpe MJ, Jerman JC, et al. The endogenous lipid anandamide is a full agonist at the human vanilloid receptor (hVR1). $\mathrm{Br}$ J Pharmacol. 2000;129:227-230.

39. Hogestatt ED, Zygmunt PM, Petersson J, et al. Vanilloid receptors on sensory nerves mediate the vasodilator action of anandamide. Nature. 1999;400:452-457.

40. Adams IB, Compton DR, Martin BR. Assessment of anandamide interaction with the cannabinoid brain receptor: SR 141716A antagonism studies in mice and autoradiographic analysis of receptor binding in rat brain. J Pharmacol Exp Ther. 1998;284:1209-1217.

41. Smith PB, Compton DR, Welch SP, Razdan RK, Mechoulam R, Martin BR. The pharmacological activity of anandamide, a putative endogenous cannabinoid, in mice. J Pharmacol Exp Ther. 1994;270:219-227.

42. Stella N, Piomelli D. Receptor-dependent formation of endogenous cannabinoids in cortical neurons. Eur J Pharmacol. 2001;425:189-196.

43. Jung K-M, Mangieri R, Stapleton C, et al. Stimulation of endocannabinoid formation in brain slice cultures through activation of group I metabotropic glutamate receptors. Mol Pharmacol. 2005;68:1196-1202.

44. Sugiura T. Evidence that the cannabinoid CB1 receptor is a 2-arachidonoylglycerol receptor. Structure-activity relationship of 2-arachidonoylglycerol, ether-linked analogues, and related compounds. J Biol Chem. 1999;274:2794-2801.

45. Sugiura T. Evidence that 2-arachidonoylglycerol but not $\mathrm{N}$-palmitoylethanolamine or anandamide is the physiological ligand for the cannabinoid CB2 receptor. J Biol Chem. 2000;275:605-612.

46. Ben-Shabat S, Fride E, Sheskin T, et al. An entourage effect: inactive endogenous fatty acid glycerol esters enhance 2-arachidonoylglycerol cannabinoid activity. Eur J Pharmacol. 1998;353:23-31.

47. Cravatt BF, Giang DK, Mayfield SP, Boger DL, Lerner RA, Gilula NB. Molecular characterization of an enzyme that degrades neuromodulatory fatty-acid amides. Nature. 1996;384:83-87.
48. Deutsch DG, Chin SA. Enzymatic synthesis and degradation of anandamide, a cannabinoid receptor agonist. Biochem Pharmacol. 1993;46:791-796.

49. Di Marzo V, Bisogno T, Melck D, et al. Interactions between synthetic vanilloids and the endogenous cannabinoid system. FEBS Lett. 1998;436:449-454.

50. Huang SM, Bisogno T, Trevisani M, et al. An endogenous capsaicinlike substance with high potency at recombinant and native vanilloid VR1 receptors. Proc Natl Acad Sci USA. 2002;99:8400-8405.

51. Dinh TP, Carpenter D, Leslie FM, et al. Brain monoglyceride lipase participating in endocannabinoid inactivation. Proc Natl Acad Sci USA. 2002;99:10819-10824.

52. Hohmann AG, Suplita RL, Bolton NM, et al. An endocannabinoid mechanism for stress-induced analgesia. Nature. 2005;435:1108-1112.

53. Egertová M, Cravatt BF, Elphick MR. Comparative analysis of fatty acid amide hydrolase and $\mathrm{cb}(1)$ cannabinoid receptor expression in the mouse brain: evidence of a widespread role for fatty acid amide of endocannabinoid signaling. Neuroscience. 2003;119:481-496.

54. Egertov M, Giang DK, Cravatt BF, Elphick MR. A new perspective on cannabinoid signalling: complementary localization of fatty acid amide hydrolase and the CB1 receptor in rat brain. Proc R Soc Lond B Biol Sci. 1998;265:2081-2085.

55. Tsou K, Nogueron MI, Muthian S, et al. Fatty acid amide hydrolase is located preferentially in large neurons in the rat central nervous system as revealed by immunohistochemistry. Neurosci Lett. 1998;254:137-140.

56. Wilson RI, Nicoll RA. Endogenous cannabinoids mediate retrograde signalling at hippocampal synapses. Nature. 2001;410:588-592.

57. Wilson RI, Nicoll RA. Endocannabinoid signaling in the brain. Science. 2002;296:678-682.

58. Goparaju SK, Ueda N, Yamaguchi H, Yamamoto S. Anandamide amidohydrolase reacting with 2-arachidonoylglycerol, another cannabinoid receptor ligand. FEBS Lett. 1998;422:69-73.

59. Gulyas AI, Cravatt BF, Bracey MH, et al. Segregation of two endocannabinoid-hydrolyzing enzymes into pre- and postsynaptic compartments in the rat hippocampus, cerebellum and amygdala. Eur J Neurosci. 2004;20:441-458.

60. Dinh TP, Kathuria S, Piomelli D. RNA interference suggests a primary role for monoacylglycerol lipase in the degradation of the endocannabinoid 2-arachidonoylglycerol. Mol Pharmacol. 2004;66:1260-1264.

61. Lichtman AH, Hawkins EG, Griffin G, Cravatt BF. Pharmacological activity of fatty acid amides is regulated, but not mediated, by fatty acid amide hydrolase in vivo. $J$ Pharmacol Exp Ther. 2002;302:73-79.

62. Ledent C, Valverde O, Cossu G, et al. Unresponsiveness to cannabinoids and reduced addictive effects of opiates in CB1 receptor knockout mice. Science. 1999;283:401-404.

63. Cravatt BF, Demarest K, Patricelli MP, et al. Supersensitivity to anandamide and enhanced endogenous cannabinoid signaling in mice lacking fatty acid amide hydrolase. Proc Natl Acad Sci USA. 2001;98:9371-9376.

64. Cravatt BF, Saghatelian A, Hawkins EG, Clement AB, Bracey MH, Lichtman AH. Functional disassociation of the central and peripheral fatty acid amide signaling systems. Proc Natl Acad Sci USA. 2004;101:10821-10826.

65. Rinaldi-Carmona M, Barth F, Heaulme M, et al. SR141716A, a potent and selective antagonist of the brain cannabinoid receptor. FEBS Lett. 1994;350:240-244. 


\section{The AAPS Journal 2006; 8 (4) Article 79 (http://www.aapsj.org).}

66. Showalter VM, Compton DR, Martin BR, Abood ME. Evaluation of binding in a transfected cell line expressing a peripheral cannabinoid receptor (CB2): identification of cannabinoid receptor subtype selective ligands. J Pharmacol Exp Ther. 1996;278:989-999.

67. Palmer SL, Thakur GA, Makriyannis A. Cannabinergic ligands. Chem Phys Lipids. 2002;121:3-19.

68. Kathuria S, Gaetani S, Fegley D, et al. Modulation of anxiety through blockade of anandamide hydrolysis. Nat Med. 2003;9:76-81.

69. Bisogno T, Melck D, De Petrocellis L, et al. Arachidonoylserotonin and other novel inhibitors of fatty acid amide hydrolase. Biochem Biophys Res Commun. 1998;248:515-522.

70. Makara JK, Mor M, Fegley D, et al. Selective inhibition of 2-AG hydrolysis enhances endocannabinoid signaling in hippocampus. Nat Neurosci. 2005;8:1139-1141.

71. Kozak KR, Prusakiewicz JJ, Marnett LJ. Oxidative metabolism of endocannabinoids by COX-2. Curr Pharm Des. 2004;10:659-667.

72. Moore SA, Nomikos GG, Dickason-Chesterfield AK, et al. Identification of a high-affinity binding site involved in the transport of endocannabinoids. Proc Natl Acad Sci USA. 2005;102:17852-17857.

73. Jarrahian A, Manna S, Edgemond WS, Campbell WB, Hillard CJ. Structure-activity relationships among $\mathrm{N}$-arachidonylethanolamine (Anandamide) head group analogues for the anandamide transporter. J Neurochem. 2000;74:2597-2606.

74. Beltramo M, Stella N, Calignano A, Lin SY, Makriyannis A, Piomelli D. Functional role of high-affinity anandamide transport, as revealed by selective inhibition. Science. 1997;277:1094-1097.

75. De Petrocellis L, Bisogno T, Davis JB, Pertwee RG, Di Marzo V. Overlap between the ligand recognition properties of the anandamide transporter and the VR1 vanilloid receptor: inhibitors of anandamide uptake with negligible capsaicin-like activity. FEBS Lett. 2000;483:52-56.

76. Dixon WE. The pharmacology of cannabis. Indica Brit Med J. 1899;2:1354-1357.

77. Bicher HI, Mechoulam R. Pharmacological effects of two active constituents of marihuana. Arch Int Pharmacodyn Ther.

1968;172:24-31.

78. Kosersky DS, Dewey WL, Harris LS. Antipyretic, analgesic and anti-inflammatory effects of delta 9-tetrahydrocannabinol in the rat. Eur J Pharmacol. 1973;24:1-7.

79. Bloom AS, Dewey WL, Harris LS, Brosius KK. 9-nor-9betahydroxyhexahydrocannabinol, a cannabinoid with potent antinociceptive activity: comparisons with morphine. J Pharmacol Exp Ther. 1977;200:263-270.

80. Buxbaum DM. Analgesic activity of 9-tetrahydrocannabinol in the rat and mouse. Psychopharmacologia. 1972;25:275-280.

81. Martin BR, Compton DR, Thomas BF, et al. Behavioral, biochemical, and molecular modeling evaluations of cannabinoid analogs. Pharmacol Biochem Behav. 1991;40:471-478.

82. Drew LJ, Harris J, Millns PJ, Kendall DA, Chapman V. Activation of spinal cannabinoid 1 receptors inhibits $\mathrm{C}$-fibre driven hyperexcitable neuronal responses and increases [35S]GTPgammaS binding in the dorsal horn of the spinal cord of noninflamed and inflamed rats. Eur J Neurosci. 2000;12:2079-2086.

83. Harris J, Drew LJ, Chapman V. Spinal anandamide inhibits nociceptive transmission via cannabinoid receptor activation in vivo. Neuroreport. 2000;11:2817-2819.

84. Hohmann AG, Martin WJ, Tsou K, Walker JM. Inhibition of noxious stimulus-evoked activity of spinal cord dorsal horn neurons by the cannabinoid WIN 55,212-2. Life Sci. 1995;56:2111-2118.
85. Hohmann AG, Tsou K, Walker JM. Cannabinoid modulation of wide dynamic range neurons in the lumbar dorsal horn of the rat by spinally administered WIN55,212-2. Neurosci Lett. 1998;257:119-122.

86. Hohmann AG, Tsou K, Walker JM. Cannabinoid suppression of noxious heat-evoked activity in wide dynamic range neurons in the lumbar dorsal horn of the rat. J Neurophysiol. 1999;81:575-583.

87. Kelly S, Chapman V. Selective cannabinoid CB1 receptor activation inhibits spinal nociceptive transmission in vivo. J Neurophysiol. 2001;86:3061-3064.

88. Martin WJ, Hohmann AG, Walker JM. Suppression of noxious stimulus-evoked activity in the ventral posterolateral nucleus of the thalamus by a cannabinoid agonist: correlation between electrophysiological and antinociceptive effects. J Neurosci. 1996;16:6601-6611.

89. Meng ID, Manning BH, Martin WJ, Fields HL. An analgesia circuit activated by cannabinoids. Nature. 1998;395:381-384.

90. Strangman NM, Walker JM. Cannabinoid WIN 55,212-2 inhibits the activity-dependent facilitation of spinal nociceptive responses. J Neurophysiol. 1999;82:472-477.

91. Hohmann AG, Tsou K, Walker JM. Intrathecal cannabinoid administration suppresses noxious stimulus-evoked Fos protein-like immunoreactivity in rat spinal cord: comparison with morphine. Acta Pharmacol Sin. 1999;20:1132-1136.

92. Tsou K, Lowitz KA, Hohmann AG, et al. Suppression of noxious stimulus-evoked expression of FOS protein-like immunoreactivity in rat spinal cord by a selective cannabinoid agonist. Neuroscience. 1996;70:791-798.

93. Elmes SJ, Jhaveri MD, Smart D, Kendall DA, Chapman V. Cannabinoid CB2 receptor activation inhibits mechanically evoked responses of wide dynamic range dorsal horn neurons in naive rats and in rat models of inflammatory and neuropathic pain. Eur J Neurosci. 2004;20:2311-2320.

94. Hunt SP, Pini A, Evan G. Induction of c-fos-like protein in spinal cord neurons following sensory stimulation. Nature. 1987;328:632-634.

95. Farquhar-Smith WP, Jaggar SI, Rice AS. Attenuation of nerve growth factor-induced visceral hyperalgesia via cannabinoid $\mathrm{CB}(1)$ and CB(2)-like receptors. Pain. 2002;97:11-21.

96. Martin WJ, Loo CM, Basbaum AI. Spinal cannabinoids are antiallodynic in rats with persistent inflammation. Pain. 1999;82:199-205.

97. Nackley AG, Makriyannis A, Hohmann AG. Selective activation of cannabinoid CB2 receptors suppresses spinal Fos protein expression and pain behavior in a rat model of inflammation. Neuroscience. 2003;119:747-757.

98. Finn DP, Jhaveri MD, Beckett SR, et al. Effects of direct periaqueductal grey administration of a cannabinoid receptor agonist on nociceptive and aversive responses in rats. Neuropharmacology. 2003;45:594-604.

99. Maione S, Bisogno T, de Novellis V, et al. Elevation of endocannabinoid levels in the ventrolateral periaqueductal grey through inhibition of fatty acid amide hydrolase affects descending nociceptive pathways via both CB1 and TRPV1 receptors. J Pharmacol Exp Ther. 2005;316:969-982.

100. Gutierrez T, Nackley AG, Neely MH, Freeman KG, Edwards GL, Hohmann AG. Effects of neurotoxic destruction of descending noradrenergic pathways on cannabinoid antinociception in models of acute and tonic nociception. Brain Res. 2003;987:176-185.

101. Herzberg U, Eliav E, Dorsey JM, Gracely RH, Kopin IJ. NGF involvement in pain induced by chronic constriction injury of the rat sciatic nerve. Neuroreport. 1997;8:1613-1618. 


\section{The AAPS Journal 2006; 8 (4) Article 79 (http://www.aapsj.org).}

102. Bridges D, Ahmad K, Rice AS. The synthetic cannabinoid WIN55,212-2 attenuates hyperalgesia and allodynia in a rat model of neuropathic pain. Br J Pharmacol. 2001;133:586-594.

103. Mao J, Price DD, Lu J, Keniston L, Mayer DJ. Two distinctive antinociceptive systems in rats with pathological pain. Neurosci Lett. 2000;280:13-16.

104. Farquhar-Smith WP, Egertova M, Bradbury EJ, McMahon SB, Rice AS, Elphick MR. Cannabinoid CB(1) receptor expression in rat spinal cord. Mol Cell Neurosci. 2000;15:510-521.

105. Arner S, Meyerson BA. Lack of analgesic effect of opioids on neuropathic and idiopathic forms of pain. Pain. 1988;33:11-23.

106. Chapman V. Functional changes in the inhibitory effect of spinal cannabinoid $(\mathrm{CB})$ receptor activation in nerve injured rats.

Neuropharmacology. 2001;41:870-877.

107. Fox A, Kesingland A, Gentry C, et al. The role of central and peripheral Cannabinoid1 receptors in the antihyperalgesic activity of cannabinoids in a model of neuropathic pain. Pain. 2001;92:91-100.

108. Monhemius R, Azami J, Green DL, Roberts MH. CB1 receptor mediated analgesia from the Nucleus Reticularis Gigantocellularis pars alpha is activated in an animal model of neuropathic pain. Brain Res. 2001;908:67-74.

109. Landsman RS, Burkey TH, Consroe P, Roeske WR, Yamamura HI. SR141716A is an inverse agonist at the human cannabinoid CB1 receptor. Eur J Pharmacol. 1997;334:R1-R2.

110. Rice AS, Beaulieu P, Bisogno T, et al. Role of the endogenous cannabinoid system in the formalin test of persistent pain in the rat. Eur J Pharmacol. 2000;396:85-92.

111. Lichtman AH, Martin BR. Spinal and supraspinal components of cannabinoid-induced antinociception. J Pharmacol Exp Ther. 1991;258:517-523.

112. Martin WJ, Lai NK, Patrick SL, Tsou K, Walker JM.

Antinociceptive actions of cannabinoids following intraventricular administration in rats. Brain Res. 1993;629:300-304.

113. Lichtman AH, Cook SA, Martin BR. Investigation of brain sites mediating cannabinoid-induced antinociception in rats: evidence supporting periaqueductal gray involvement. J Pharmacol Exp Ther. 1996;276:585-593.

114. Martin WJ, Coffin PO, Attias E, Balinsky M, Tsou K, Walker JM. Anatomical basis for cannabinoid-induced antinociception as revealed by intracerebral microinjections. Brain Res. 1999;822:237-242.

115. Martin WJ, Patrick SL, Coffin PO, Tsou K, Walker JM. An examination of the central sites of action of cannabinoid-induced antinociception in the rat. Life Sci. 1995;56:2103-2109.

116. Martin WJ, Tsou K, Walker JM. Cannabinoid receptor-mediated inhibition of the rat tail-flick reflex after microinjection into the rostral ventromedial medulla. Neurosci Lett. 1998;242:33-36.

117. Finn DP, Jhaveri MD, Beckett SR, Kendall DA, Marsden CA, Chapman V. Cannabinoids modulate ultrasound-induced aversive responses in rats. Psychopharmacology (Berl). 2004;172:41-51.

118. Cannon JT, Prieto GJ, Lee A, Liebeskind JC. Evidence for opioid and non-opioid forms of stimulation-produced analgesia in the rat. Brain Res. 1982;243:315-321.

119. Reynolds DV. Surgery in the rat during electrical analgesia induced by focal brain stimulation. Science. 1969;164:444-445.

120. Walker JM, Huang SM, Strangman NM, Tsou K, Sanudo-Pena MC. Pain modulation by release of the endogenous cannabinoid anandamide. Proc Natl Acad Sci USA. 1999;96:12198-12203.

121. Suplita RL, II, Farthing JN, Gutierrez T, Hohmann AG. Inhibition of fatty-acid amide hydrolase enhances cannabinoid stress-induced analgesia: sites of action in the dorsolateral periaqueductal gray and rostral ventromedial medulla. Neuropharmacology. 2005;49:1201-1209.

122. Vaughan CW, Connor M, Bagley EE, Christie MJ. Actions of cannabinoids on membrane properties and synaptic transmission in rat periaqueductal gray neurons in vitro. Mol Pharmacol. 2000;57:288-295.

123. Palazzo E, Marabese I, de Novellis V, et al. Metabotropic and NMDA glutamate receptors participate in the cannabinoid-induced antinociception. Neuropharmacology. 2001;40:319-326.

124. Vaughan CW, McGregor IS, Christie MJ. Cannabinoid receptor activation inhibits GABAergic neurotransmission in rostral ventromedial medulla neurons in vitro. Br J Pharmacol. 1999; 127:935-940.

125. Meng ID, Johansen JP. Antinociception and modulation of rostral ventromedial medulla neuronal activity by local microinfusion of a cannabinoid receptor agonist. Neuroscience. 2004;124:685-693.

126. Davis M, Whalen PJ. The amygdala: vigilance and emotion. $\mathrm{Mol}$ Psychiatry. 2001;6:13-34.

127. Marsicano G, Wotjak CT, Azad SC, et al. The endogenous cannabinoid system controls extinction of aversive memories. Nature. 2002;418:530-534.

128. Medina JF, Repa CJ, Mauk MD, LeDoux JE. Parallels between cerebellum- and amygdala-dependent conditioning. Nat Rev Neurosci. 2002;3:122-131.

129. Helmstetter FJ, Bellgowan PS, Poore LH. Microinfusion of mu, but not delta or kappa opioid agonists into the basolateral amygdala results in inhibition of the tail flick reflex in pentobarbital-anesthetized rats. J Pharm Exp Ther. 1995;275:381-388.

130. Helmstetter FJ, Bellgowan PS, Tershner SA. Modulation of spinal nociceptive reflexes by the microinjection of morphine into the amygdala. Neuroreport. 1993;4:471-474.

131. Manning BH, Mayer DJ. The central nucleus of the amygdala contributes to the production of morphine antinociception in the rat tailflick test. J Neurosci. 1995;15:8199-8213.

132. Manning BH, Merin NM, Meng ID, Amaral DG. Reduction in opioid- and cannabinoid-induced antinociception in rhesus monkeys after bilateral lesions of the amygdaloid complex. J Neurosci. 2001;21:8238-8246.

133. Manning BH, Martin WJ, Meng ID. The rodent amygdala contributes to the production of cannabinoid-induced antinociception. Neuroscience. 2003;120:1157-1170.

134. Helmstetter FJ. The amygdala is essential for the expression of conditional hypoalgesia. Behav Neurosci. 1992;106:518-528.

135. Helmstetter FJ, Bellgowan PS. Lesions of the amygdala block conditional hypoalgesia on the tail flick test. Brain Res. 1993;612:253-257.

136. Bellgowan PS, Helmstetter FJ. Neural systems for the expression of hypoalgesia during nonassociative fear. Behav Neurosci. 1996;110:727-736.

137. Akil H, Young E, Walker JM, Watson SJ. The many possible roles of opioids and related peptides in stress-induced analgesia. Ann N Y Acad Sci. 1986;467:140-153.

138. Lewis JW, Cannon JT, Liebeskind JC. Opioid and nonopioid mechanisms of stress analgesia. Science. 1980;208:623-625.

139. Terman GW, Lewis JW, Liebeskind JC. Two opioid forms of stress analgesia: studies of tolerance and cross-tolerance. Brain Res. 1986;368:101-106.

140. Finn DP, Beckett SR, Richardson D, Kendall DA, Marsden CA, Chapman V. Evidence for differential modulation of conditioned 
The AAPS Journal 2006; 8 (4) Article 79 (http://www.aapsj.org).

aversion and fear-conditioned analgesia by $\mathrm{CB} 1$ receptors. Eur $J$ Neurosci. 2004;20:848-852.

141. Suplita RL, II, Gutierrez T, Fegley D, Piomelli D, Hohmann AG. Endocannabinoids at the spinal level regulate, but do not mediate, nonopioid stress-induced analgesia. Neuropharmacology. 2005;262:25.

142. Heinricher MM, Morgan MM, Tortorici V, Fields HL. Disinhibition of off-cells and antinociception produced by an opioid action within the rostral ventromedial medulla. Neuroscience. 1994;63:279-288.

143. Smith PB, Martin BR. Spinal mechanisms of delta 9-tetrahydrocannabinol-induced analgesia. Brain Res. 1992;578: 8-12.

144. Welch SP, Stevens DL. Antinociceptive activity of intrathecally administered cannabinoids alone, and in combination with morphine, in mice. J Pharmacol Exp Ther. 1992;262:10-18.

145. Welch SP, Thomas C, Patrick GS. Modulation of cannabinoidinduced antinociception after intracerebroventricular versus intrathecal administration to mice: possible mechanisms for interaction with morphine. J Pharmacol Exp Ther. 1995;272:310-321.

146. Yaksh TL. The antinociceptive effects of intrathecally administered levonantradol and desacetyllevonantradol in the rat. J Clin Pharmacol. 1981;21:334S-340S.

147. Richardson JD, Aanonsen L, Hargreaves KM. Antihyperalgesic effects of spinal cannabinoids. Eur J Pharmacol. 1998;345:145-153.

148. Cannich A, Wotjak CT, Kamprath K, Hermann H, Lutz B, Marsicano G. CB1 cannabinoid receptors modulate kinase and phosphatase activity during extinction of conditioned fear in mice. Learn Mem. 2004;11:625-632.

149. Bernard JF, Bester H, Besson JM. Involvement of the spinoparabrachio-amygdaloid and -hypothalamic pathways in the autonomic and affective emotional aspects of pain. Prog Brain Res. 1996;107:243-255.

150. Katona I, Rancz EA, Acsady L, et al. Distribution of CB1 cannabinoid receptors in the amygdala and their role in the control of GABAergic transmission. J Neurosci. 2001;21:9506-9518.

151. Connell K, Bolton N, Olsen D, Piomelli D, Hohmann AG. Role of the basolateral nucleus of the amygdala in endocannabinoid-mediated stress-induced analgesia. Neurosci Lett. 2005;12:22.

152. Valverde O, Ledent C, Beslot F, Parmentier M, Roques BP. Reduction of stress-induced analgesia but not of exogenous opioid effects in mice lacking CB1 receptors. Eur J Neurosci. 2000;12:533-539.

153. Atkinson JH, Slater MA, Wahlgren DR, et al. Effects of noradrenergic and serotonergic antidepressants on chronic low back pain intensity. Pain. 1999;83:137-145.

154. Portenoy RK, Foley KM. Chronic use of opioid analgesics in nonmalignant pain: report of 38 cases. Pain. 1986;25:171-186.

155. Cravatt BF, Lichtman AH. Fatty acid amide hydrolase: an emerging therapeutic target in the endocannabinoid system. Curr Opin Chem Biol. 2003;7:469-475.

156. Yesilyurt O, Dogrul A, Gul H, et al. Topical cannabinoid enhances topical morphine antinociception. Pain. 2003;105:303-308. 